Experi ments and Dynamic Fi ni te El ement Anal ysi s of a Wre-Rope Rockf al I Prot ect i ve Fence

\begin{tabular}{|l|l|}
\hline 著者 & Van Phuc Tran, Negawa Koj i , Fukada Sai j i \\
\hline $\begin{array}{l}\text { j our nal or } \\
\text { publ i cat i on t i t l e }\end{array}$ & Rock Nechani cs and Rock Engi neer i ng \\
\hline vol une & 46 \\
\hline number & 5 \\
\hline page r ange & 1183 - 1198 \\
\hline year & $2013-09-01$ \\
\hline URL & ht t p: //hdl . handl e. net /2297/33419 \\
\hline
\end{tabular}




\title{
Experiments and dynamic finite element analysis of a wire-rope rockfall protective fence
}

\author{
Phuc Tran Van ${ }^{1 *}$, Koji Maegawa ${ }^{2}$, Saiji Fukada ${ }^{2}$ \\ ${ }^{1}$ Graduate School of Natural Science and Technology, Kanazawa University \\ ${ }^{2}$ Faculty of Environmental Design, Kanazawa University
}

\author{
Corresponding author: \\ Phuc Tran Van \\ Graduate School of Natural Science and Technology, \\ Kanazawa University \\ NST-2C313, Kakuma machi, Kanazawa, Ishikawa 920-1192, Japan \\ $+81-76-234-4602$ \\ phucjp@stu.kanazawa-u.ac.jp
}




\section{Abstract}

The imperative need to protect structures in mountainous areas against rockfall has led to the development of various protection methods. This study introduces a new type of rockfall protection fence made of posts, wire ropes, wire netting and energy absorbers. The performance of this rock fence was verified in both experiments and dynamic finite element analysis. In collision tests, a reinforcedconcrete block rolled down a natural slope and struck the rock fence at the end of the slope. A specialized system of measuring instruments was employed to accurately measure the acceleration of the block without cable connection. In particular, the performance of two energy absorbers, which contribute also to preventing wire ropes from breaking, was investigated to determine the best energy absorber. In numerical simulation, a commercial finite element code having explicit dynamic capabilities was employed to create models of the two full-scale tests. To facilitate simulation, certain simplifying assumptions for mechanical data of each individual component of the rock fence and geometrical data of the model were adopted. Good agreement between numerical simulation and experimental data validated the numerical simulation. Furthermore, the results of numerical simulation helped highlight limitations of the testing method. The results of numerical simulation thus provide a deeper understanding of the structural behavior of individual components of the rock fence during rockfall impact. More importantly, numerical simulations can be used not only as supplements to or substitutes for full-scale tests but also in parametric study and design.

Keywords: rock fence, numerical simulation, rockfall, energy absorber, wire rope 


\section{Introduction}

Many methods of protecting against rockfall have been devised around the world. They can be classified into prevention and protection types. A prevention method involves the removal or stabilization of dangerous rocks on a slope. A protection method uses interceptive structures such as an embankment, a rock shed or a rock fence to catch rockfall in the middle or at the end of a slope.

An embankment has the advantage of lower construction and repair costs and the capacity to absorb higher rockfall energy than other structures, but it requires a suitable construction site. The embankment approach has been experimentally and numerically analyzed (Ronco et al. 2009; Lambert et al. 2009; Maegawa et al. 2011).

Many rock sheds have been constructed for mountainous roads in Japan. Impact tests have been carried out on a real rock shed to confirm its ultimate capacity (Kishi et al. 2002). However, the design basis for a rock shed in the Rockfall Mitigation Handbook (Japan Road Association 2006) is allowable stress design and leads to underestimation of the performance-cost ratio of a rock shed compared with the other structures.

The principal advantages of a rock fence are its rapid erection and easy maintenance. Some countries such as Japan, Italy, Switzerland, France and the United States have developed many types of rock fence. For instance, different types of fence were tested at a field test site in Europe, and flexible and practicable solutions for designing and constructing a rock fence were established as guidelines for the approval of rockfall protection kits (Gerber 2001; ETAG-027 2008). A flexible rock fence made from polyethylene netting, which is resistant against alkalis, acids, water, sudden impact, low temperature and ultraviolet rays and can withstand high rockfall energy, was developed in Japan (Maegawa 2006). Rock fences made from netting have the important feature of being able to absorb rockfall energy through their flexibility, which is achieved by large displacement of the cable net and by energy-dissipating devices mounted on the connecting cables.

In this study, a new type of rock fence made of posts, wire ropes, wire netting and energy absorbers is shown to have a remarkable capacity to catch rocks and thereby prevent damage to vehicles and houses, as well as fatalities. Basically, 
with regarding self-standing and accordance with narrow spaces of the fence, it was designed with an adequate stiffness without lateral guy cables and anchors. Moreover in Japan, the design scheme for a rock fence is based on a desired energy-absorption capacity (Japan Road Association 2006). To absorb a large amount of energy, the wire rope of the rock fence is semi-fastened to a post using an energy-absorbing device (Maegawa et al. 1995) as shown in Fig. 1 in which and following figures the default unit of dimensions is millimeter. When pulled, the wire rope does not slip from the device until the magnitude of the friction force exceeds a critical value, which is possible to vary. As the wire rope slips, the device is able to maintain a fluctuating kinetic frictional force between it and the wire rope until a stopper located at the end of the rope comes into contact with the energy absorber. The wire rope thus does not break and part of the impact energy is absorbed by the energy absorber.

Two types of energy absorber will be introduced and examined with respect to their configuration and corresponding energy-dissipation behavior. To reduce the number of energy absorbers and achieve lower cost while maintaining performance, energy absorbers were installed only at the end posts of the new type of fence. This type of rock fence was examined in full-scale experiments carried out using a reinforced-concrete (RC) block that rolled down a natural slope without a navigation system. Since an RC block under this experimental condition has not only translational motion but also rotational motion, the composite effect of the natural motion on the performance of the rock fence will be clear. In preparation for these tests, laboratory pre-tests on such components as energy absorbers and posts were conducted to confirm their load-carrying capacities and structural behaviors. Additionally, an experimental control system was devised to investigate the impact force between the block and fence in the tests.

Moreover, to obtain a deeper understanding of the structural behavior of the fence, numerical simulation has been performed using the finite element code LSDYNA. The emphasis here is on the methodology; i.e., how to apply the dynamic finite element analysis to a prototype of a rock fence having some new characteristics.

In the numerical approach, first and foremost the numerical models were validated by comparing the results with those obtained in real-scale tests. The numerical 
simulation was then useful for parametric analysis. Iterative execution allowed us to examine the structural function of each individual component of the fence and how these components interact with one another during rockfall impact. Additionally, a series of numerical simulations was carried out to examine the effect of the impact location on the resistance of the fence, which could not be done experimentally, and to verify the rockfall energy absorption capacity of the fence under various impact conditions.

\section{Configuration of the Rock Fence}

\subsection{Details of the Rock Fence}

Figure 2 shows the configuration and dimensions of the rock fence. Four posts made of concrete-filled steel tubes were vertically erected with a rigid joint on a concrete foundation, forming three spans with unequal length of 5, 8, and $5 \mathrm{~m}$. These unequal dimensions come from the site condition that was just fit for the fence of $18 \mathrm{~m}$ long. Fortunately, it is certain that elongation of the $18 \mathrm{~m}$ long fence is smaller than that of equal length of 8,8 , and $8 \mathrm{~m}$ fence; i.e., likely safer to use the fence of $18 \mathrm{~m}$ in this study. Fourteen wire ropes employed as main components to catch rockfall were horizontally installed by connecting to both end posts via energy absorbers that are effective in preventing the wire ropes from breaking. Each wire rope passed a steel-ring welded to intermediate posts. The extension length of each wire rope from the energy absorber was $1400 \mathrm{~mm}$, and a stopper was attached at the end of each wire rope to prevent the rope from sliding out of the energy absorber. Additionally, seven vertical braces of steel plates were installed at mid-span of the fence to help maintain the spacing between wire ropes. The vertical brace semi-fastened each wire rope by two wire clips. With the aim of supporting the wire ropes to catch rockfall, two layers of wire netting comprising 5-mm steel wire having grid spacing of $50 \mathrm{~mm}$ were used. The wire netting and wire rope were connected by several steel-wire coils. To brace the posts against one another in the plane of the fence, the top of each adjacent post was connected to a steel pipe functioning as a horizontal brace.

As shown in Fig. 1, two types of energy absorber were used in full-scale tests. The energy absorber consisted of a U-shaped bolt and two types of steel block. Each steel block consisted of two steel plates with thicknesses of 25 to $38 \mathrm{~mm}$. The two 
steel plates were stacked one upon the other and the concave indentations of the two plates held in place a wire rope when they were compressed together by two M20 bolts at $200 \mathrm{Nm} /$ bolt. The critical friction force between wire rope and the steel plates depends on the torque of the M20 bolts. Furthermore, as shown in Fig. $1 \mathrm{a}$ and $\mathrm{b}$, the two types of energy absorber differ in the interval between the two steel blocks. In the Type-B energy absorber, the smaller steel block can initially slide along the U-bolt a distance of $60 \mathrm{~mm}$, until contacting the larger one fixed to the U-bolt. In contrast, in the Type-A energy absorber, there is no interval between the two steel blocks and both of them are fixed to the U-bolt. This difference affects the timing of the maximum rope tension during rockfall collision.

\subsection{Experimental Control System}

Figure 3 shows the experimental control system mainly aimed at measuring the rope tension and the acceleration of the RC block. To record the acceleration data of the RC block at a sampling rate of $2 \mathrm{kHz}$, a three-axis accelerometer, analog-todigital transformation recorder and transceiver were placed at the center of the RC block. The transceiver acted to start up the recorder as soon as it received the trigger signal emitted from the master transceiver. Next, another analog-to-digital transformation recorder was synchronized to accumulate the data at a sampling rate of $2 \mathrm{kHz}$ from strain gauges attached to the U-bolts of the energy absorbers. These data helped in estimating the wire-rope tension because the relation between the strain of the U-bolt and the tension force of the wire rope has been measured in a laboratory test. Additionally, a high-speed camera (600 frames/second) was set up on the side of the fence to capture the instant that the $\mathrm{RC}$ block makes impacts with the fence. Since the camera's starting frame was also synchronized, the frame number at the time of collision helped to specify the collision time in the acceleration history data. The RC block velocities were estimated from a series of frames shortly before the RC block strikes the fence. The prominent feature of this measurement system is that the accumulated data are synchronized by means of transceivers. Moreover, several other high-speed cameras (300 frames/second) were set up at the most appropriate positions to monitor the interaction between the RC block and rock fence. 


\section{Outline of the Experiments}

\subsection{Pre-testing and Results for Energy Absorbers}

Two types of energy absorber were tested in the laboratory to examine their behavior, in particular the friction force between the energy absorber and wire rope. Figure 4 describes the configuration and procedures of the laboratory test for an energy absorber. One end of the wire rope was connected to the test frame through a load cell, and the opposite part was held by an energy absorber; i.e., steel blocks. The outer wire rope from an energy absorber was free and was the extension for the sliding function. The remainder of the wire rope could be set at a length of about $5 \mathrm{~m}$ for the test, since the curved end of the U-bolt was connected to the test frame. The test procedure was as follows. A 1340-kg weight freely dropped along vertical guides and struck the middle of the wire rope, and the extension of the wire rope then slid through the energy absorber. The rope tension was measured using a load cell, and the rope slippage was calculated from the weight displacement measured using a rotary encoder connected to the weight. Additionally, the relation between the strain of each U-bolt used in the rock fence and the rope tension was examined in tensile tests under a static load. This relation was used to estimate the rope tension from the U-bolt's strain data recorded for the fence subjected to an impact load.

Figure 5 shows the results for the impulsive friction force for the two types of energy absorber. Independent of the device type, the impulsive friction force fluctuated widely, indicating that the wire rope exhibited alternate behaviors of slipping and stopping. However, the fluctuation of the Type-B energy absorber began at a lower friction force than that of the Type-A energy absorber. This difference certainly derives from the interval between the two steel blocks of the Type-B energy absorber, since the friction force initially occurred only in the larger steel block owing to this interval as mentioned in Section 2.1. No wire ropes broke during testing, and Fig. 6 shows that the maximum instantaneous friction forces for the Type-A and Type-B energy absorbers were 157 and $150 \mathrm{kN}$, respectively and they were less than the nominal strength of the wire rope (180 $\mathrm{kN}$ ). Additionally, the average values of the impulsive friction force, obtained by dividing the final potential energy of the weight by the total slippage of the wire 
rope, were 65.2 and $45.4 \mathrm{kN}$ for Type-A and Type-B energy absorbers, respectively.

\subsection{Test of the Rock Fence}

Two tests were carried out. The sole difference between the tests is that Type-A and Type-B energy absorbers were applied in Tests No. 1 and No. 2, respectively. The mass of the weight and its falling height were identical in the two tests. After Test No. 1, all components other than the posts were replaced with new ones. The shape of the RC block was in accordance with the EOTA guidelines for falling-rock protection kits (ETAG-027 2008), as shown in Fig. 3. The RC block was covered with 6-mm-thick steel plates and weighed 5.2 tons. In the tests, the block began rolling from the peak of a slope at a height of approximately $37 \mathrm{~m}$ and then stuck the fence, which was located at the bottom of the slope, as shown in Fig. 6.

\section{Results of Rock Fence Tests}

\subsection{Behavior of the Rock Fence}

Figure 7 shows the collision point marked by an octagon at the mid-span of each fence. The collision point in Test No. 1 was slightly left of center. The target was set at a height of $2.7 \mathrm{~m}$ from the concrete foundation.

Figures 8 and 9 show the impact process; i.e., the motion of the RC block and the behavior of the rock fence just before and during the collision in Test No. 1 and Test No. 2, respectively, and the peak elongation of the wire netting. These images generally indicate that the fence could decelerate and captured the RC block in both tests. However, more thorough examination of the overall behavior of the fence shows differences between the two tests.

Relating to the deformation of the fence, the peak elongation of the wire mesh in Test No. 2 was slightly larger than that in Test No. 1. Another discrepancy between two tests pertains to rope breaking. In Test No. 1, rope breaking was observed (wire ropes No. 1 through No. 7 broke, as shown in Fig. 7) and this is because the rope tension is not constant. It is higher in the impact region. In particular there was no slippage between the wire ropes and energy absorbers in 
Test No.1. In contrast, there was slipping in Test No.2 as illustrated in Fig. 10, enabling the fence to stop the RC block without the breaking of wire ropes. After each test, theodolites were used to measure post deformation expressed by a post's declination in units of degrees in different directions with reference to the vertical. Site observations showed that the end posts only inclined in the fence plane and intermediate posts only inclined in a vertical plane perpendicular to the fence plane. Table 1 showing the declination data of the posts, shows that the deformation of the end posts in Test No. 1 was greater than that in Test No. 2, again demonstrating the great efficiency of the Type-B energy absorbers. Additionally, within each test, the collision location logically affects the difference in deformation between right and left posts.

Furthermore, the deformation of vertical braces in the Y-direction perpendicular to the fence plane, particularly the vertical braces in the impact region, generally reflecting the residual shape of the fence for both tests was measured. The maximum residual deformation in both tests is $<1.1 \mathrm{~m}$.

Table 1: Deformation data for the posts in the two tests

\begin{tabular}{|c|c|c|c|c|}
\hline \multirow{2}{*}{ Posts } & \multicolumn{2}{|c|}{ End posts } & \multicolumn{2}{c|}{ Intermediate posts } \\
\cline { 2 - 5 } & Left & Right & Left & Right \\
\hline Test No. 1 & $7.4^{\circ}$ & $5.5^{\circ}$ & $7.0^{\circ}$ & $4.2^{0}$ \\
\hline Test No. 2 & $2.8^{\circ}$ & $4.1^{\circ}$ & $3.4^{0}$ & $7.7^{0}$ \\
\hline
\end{tabular}

\subsection{Impact Deceleration, Force, Velocity, and Energy}

Figures 11 and 12 show the resultant deceleration vs. time for Test No. 1 and Test No. 2, respectively, before and after collision. It is seen that the contact time can be estimated from the starting time of the high-speed camera and the frame number at which the RC block is observed striking the fence. Consequently, the deceleration and/or impact force due to the collision between the RC block and fence can be determined from the graph according to the contact time. The maximum deceleration and impact force were 280 to $340 \mathrm{~m} / \mathrm{s}^{2}$ and 1.46 to 1.77 MN, respectively. The deceleration (i.e., the impact force) in Test No. 1 was clearly larger than that in Test No. 2. This result appears to be logically related to the fact that wire ropes No. 1 through No. 7 broke in Test No. 1. According to the Japan Road Association Hand Book of Rockfall (Japan Road Association 2006), expected impact energy of approximately $1300 \mathrm{~kJ}$ was 
estimated for site conditions of slope of $41^{\circ}$, height of $37 \mathrm{~m}$, and surface friction coefficient of 0.25 . After the tests, however, the impact energy was recalculated from the block's impact velocities. The impact energy consists of translational energy $\left(E_{v}\right)$ and rotational energy $\left(E_{r}\right)$, which depend on the respective velocities of translation and rotation of the RC block just before collision:

$$
\begin{aligned}
E_{v} & =M V^{2} / 2, \quad E_{r}=I \omega^{2} / 2, \\
E & =E_{v}+E_{r},
\end{aligned}
$$

where $M, I, V$, and $\omega$ are the mass, moment of inertia, translational velocity, and rotational velocity of the RC block, respectively. These component velocities of the RC block just before collision were approximately evaluated as follows. Before the tests, two separate points were firmly marked on the ground just in front of the fence at test site. The block's translational velocity was then calculated by dividing the distance between those points by the period of time that it took the block to pass through that distance and could be estimated from the number of frames of the block motion recorded by the high-speed cameras. The block's rotational velocity was determined solely from the recording of the block motion with the support of Videopoint software.

Table 2: Velocity and impact energy

\begin{tabular}{|c|c|c|c|c|c|}
\hline Test No. & $\begin{array}{c}\text { Translation } \\
\text { Velocity } V \\
(\mathrm{~m} / \mathrm{s})\end{array}$ & $\begin{array}{c}\text { Rotation } \\
\text { Velocity } \omega \\
(\mathrm{rad} / \mathrm{s})\end{array}$ & $\begin{array}{c}\text { Translation } \\
\text { Energy } E_{v} \\
(\mathrm{~kJ})\end{array}$ & $\begin{array}{c}\text { Rotation } \\
\text { Energy } E_{r} \\
(\mathrm{~kJ})\end{array}$ & $\begin{array}{c}\text { Total } \\
\text { Energy } E \\
(\mathrm{~kJ})\end{array}$ \\
\hline 1 & 16.0 & 14.3 & 666 & 140 & 806 \\
\hline 2 & 16.8 & 16.8 & 734 & 193 & 927 \\
\hline
\end{tabular}

Table 2 gives the magnitudes of the translational and rotational velocities and the corresponding impact energies. The total impact energy was lower than the expected energy. The reason for this may be that the RC block passed through a gravel layer placed in front of the rock fence to control the trajectory of the RC block because the layers of gravel were able to function as an energy-absorbing system (Pichler et al. 2005), and more importantly, the site surface friction coefficient used for the expected energy might be inappropriate. Table 2 indicates that the rotational energy was $17 \%$ to $20 \%$ of the total impact energy. This value might be larger than the expected value (Japan Road Association 2006), because the shape of the RC block used in this experiment rotates more easily than a rock 
during actual rockfall. Despite the larger rotational energy, the RC block did not bounce over the fence because of the flexibility of the fence structure.

\section{Numerical Analysis}

\subsection{Finite Element Explicit Analysis}

Because the impact phenomenon itself has a dynamic characteristic and involves large deformations, modeling the collision of an RC-block against a rock fence in numerical simulation based on a finite element method requires the consideration of nonlinear geometrical and mechanical behavior and particularly the adequate contact conditions. For this reason, nonlinear dynamic analysis using LSDYNA_971 is adopted to simulate the impact phenomenon in this study. With appropriate computational cost, this finite-element-method code can accurately analyze the rockfall impact, which lasts for only a very short period of a few seconds and involves rapid variations in force, velocity, acceleration and contact condition.

\subsection{Assumptions}

The collision of the wire-rope rock fence subjected to rockfall can only be numerically simulated by making simplifying assumptions based on engineering judgment.

First, the typical behavior of steel cable used as wire ropes in a standard static tensile test is depicted in Fig. 13. Another typical static tensile test carried out on pieces of steel wire used as wire netting was conducted to assert their loadcarrying capacity.

In both cases, the authors are confronted with the problem of being unable to attain the dynamic material properties that should be obtained from dynamic tests. For simplicity and to retain only the most important observed characteristics of both wire rope and wire netting, the authors adopt a constitutive law that is bilinear and rate-independent. This assumption might be disputed as being too rough an approximation. However, the effect of the strain rate phenomenon on the overall performance of the fence subjected to rockfall is not so considerable because of the low speed of rockfall impact as compared with that of a blast or a projectile and according to experimental tests. Grillo et al. (1985) pointed out that 
the assumption seems appropriate for steel members under impulsive loading. Thus, Figs. 14a and 14b show the assumed stress-strain curves for wire rope and wire netting, respectively, and the ultimate strength and the corresponding permanent strain are those deduced from static tensile tests with some appropriate engineering judgments.

Figure 15 shows the configuration of the numerical model representing energy absorbers. In this model, element $\mathrm{AB}$ with material properties complying with the stress-strain curve sketched in Fig. 16a is a key component. This element should express necessary structural functions that the real energy absorbers perform. Indeed, as shown in Fig. 16b, after the yield stress point is reached, element $A B$ begins lengthening under an invariable tension force, which is not an actual fluctuating friction force but is the average value of the impulsive friction force depending on the type of energy absorber. This behavior properly simulates the phenomenon of wire rope sliding through the energy absorber and therefore ensures that the absorbed impact energy in the numerical model is similar to that for the real fence. In addition, the presence of two elements AC and BC modeled as wire rope elements prevents the elongation of element $\mathrm{AB}$ from exceeding 800 $\mathrm{mm}$, which is the peak slippage of wire ropes in Test No. 2. Indeed when points C and $\mathrm{D}$ coincide with each other, the length of element AB is approximately 900 $\mathrm{mm}$; i.e., the elongation reaches a maximum of $800 \mathrm{~mm}$.

The next important assumption is applied to the post constructed with a concretefilled steel tube. LS-DYNA does not have appropriate composite material properties to model this type of component. A simplified model for the post was therefore made using a steel tube beam element with assurance that the loadcarrying capacity and ductility of the post must be maintained. A three-point bending test on this post, which is supported by a span of $3.2 \mathrm{~m}$, was carried out to determine the performance of the post; the bending moment vs. deflection curve is sketched as a blue line in Fig. 17a. The beam of only a steel tube, which has the same outer diameter as the real post, was analyzed by searching for adequate values of thickness and Young's modulus. When the values of the thickness and Young's modulus were $30 \mathrm{~mm}$ and $120 \mathrm{GPa}$ respectively, the red line obtained from analysis matched the blue line well, as shown in Fig. 17a. From this result, the assumed stress-strain curve for the post modeled by only a steel tube is sketched in Fig. 17b. 


\subsection{Numerical Simulation}

The model used in the numerical simulation of the rock fence in Test No. 1 is referred to as Model No. 1 hereafter. Table 3 summarizes characteristics and parameters of Model No. 1. A cable element can be used to model wire rope or wire netting without consideration of the compressive force. However, because there is no definition of failure strain for the cable element in LS-DYNA, a truss element that can take a failure strain is adopted. Therefore, a pattern of alternate cable and truss elements are assigned to the wire rope and wire netting in the impact section to consider the possibility of breaking. To reduce the number of elements with the aim of reducing the execution time, the wire netting in Model No. 1 is simulated as just one layer of a $150 \mathrm{~mm} \times 150 \mathrm{~mm}$ square grid. The wire diameter of the wire netting is therefore increased to $12.24 \mathrm{~mm}$ and the effective cross-sectional area is $A_{\text {eff }}=117.63 \mathrm{~mm}^{2}$, six times the original value. In fact, it was verified that there is no noticeable difference between the results analyzed using models having different grid sizes; i.e., $50 \mathrm{~mm}$ and $150 \mathrm{~mm}$. The steel coil, which connects the wire rope and wire netting, is modeled by a K-element for which the spring constant is $10^{5} \mathrm{~N} / \mathrm{m}$. The average friction force of $65 \mathrm{kN}$ is applied for the energy absorber; i.e., Type A for Model No.1.

Table 3: Numerical data of Model No. 1

\begin{tabular}{|l|l|l|l|l|}
\hline $\begin{array}{l}\text { Structural } \\
\text { Component }\end{array}$ & $\begin{array}{l}\text { Type of } \\
\text { Element }\end{array}$ & Type of Material & $\begin{array}{l}\text { Constitutive } \\
\text { Law }\end{array}$ & $\begin{array}{l}\text { Sectional } \\
\text { Properties } \\
{[\mathrm{mm}]}\end{array}$ \\
\hline Wire rope & $\begin{array}{l}\text { a) Beam-Cable } \\
\text { b) Beam-Truss }\end{array}$ & $\begin{array}{l}\text { a) Cable Discrete } \\
\text { b) Piecewise } \\
\text { Linear Plasticity }\end{array}$ & Fig. 14a & $\varnothing 18$ \\
\hline Wire netting & $\begin{array}{l}\text { a) Beam-Cable } \\
\text { b) Beam-Truss }\end{array}$ & $\begin{array}{l}\text { a) Cable Discrete } \\
\text { b) Piecewise } \\
\text { Linear Plasticity }\end{array}$ & Fig. 14b & $\varnothing 5$ \\
\hline Post & Beam & $\begin{array}{l}\text { Piecewise Linear } \\
\text { Plasticity }\end{array}$ & Fig. 17b & $\varnothing 267.4 \times 30 \mathrm{t}$ \\
\hline Horizontal & Beam & $\begin{array}{l}\text { Piecewise Linear } \\
\text { Plasticity }\end{array}$ & Fig. 14b & $\varnothing 14.3 \times 4.5 \mathrm{t}$ \\
\hline Vertical & Shell & Piecewise Linear & Fig. 14b & $9 \mathrm{t}$ \\
\hline
\end{tabular}




\begin{tabular}{|l|l|l|l|l|}
\hline Brace & Plasticity & & \\
\hline $\begin{array}{l}\text { Steel ring } \\
\text { welded to } \\
\text { post }\end{array}$ & Beam & Rigid & $\varnothing 30$ \\
\hline $\begin{array}{l}\text { U-bolts } \\
\text { connected to } \\
\text { vertical brace }\end{array}$ & Beam & Rigid & & $\varnothing 10$ \\
\hline
\end{tabular}

Furthermore, the consideration of the probable interaction of components within the fence during the impact is critical to achieving a good result. The automaticcontact definition used in Model No. 1 is based on the penalty method, which involves placing normal interface springs between all penetrating nodes and the contact surface. Table 4 presents the automatic contact definitions applied for components that probably interact with one another within Model No. 1.

Table 4: Automatic contact definitions for Model No. 1

\begin{tabular}{|l|l|}
\hline Contact definitions & Components in contact \\
\hline Automatic General & $\begin{array}{l}\text { (wire rope vs. steel ring) ; (wire rope vs. } \\
\text { vertical brace) ; (weight vs. vertical brace) }\end{array}$ \\
\hline Automatic Nodes to Surface & $\begin{array}{l}\text { (weight vs. wire netting) ; (weight vs. wire } \\
\text { rope) }\end{array}$ \\
\hline
\end{tabular}

Figure 18 illustrates the geometry of the wire-rope rock fence built in LS-DYNA, including the colliding block. Initially, the fence vertically stands in a plane and the trajectory of the colliding RC block lies in a vertical plane perpendicular to the fence plane. The block is modeled according to its real shape. According to EOTA guidelines (ETAG-027 2008), the volume of the block can be calculated as $V=17 / 24 \times D^{3}$, where $D$ is the maximum size of the RC block (1408 mm). Elastic-solid elements are assigned to the block with mass density of $2.63 \times 10^{-9}$ ton $/ \mathrm{mm}^{3}$, giving a weight of the block of 5.2 ton. The block is placed immediately next to the fence plane and assigned initial conditions of angular velocity $\omega=14.3$ $\mathrm{rad} / \mathrm{s}$, translational velocity in the $Y$ direction (normal to the fence plane) $v_{y}=15.8$ $\mathrm{m} / \mathrm{s}$, and translational velocity in the $Z$ direction $v_{z}=2.3 \mathrm{~m} / \mathrm{s}$; these values were obtained from the results for Test No. 1. 
Model No. 2 simulating Test No. 2 is similar to Model No. 1 on the whole, but the average friction force of $45 \mathrm{kN}$ is applied for the energy absorber; i.e., Type B for Model No. 2. The initial conditions of the RC block are angular velocity $\omega=16.8$ $\mathrm{rad} / \mathrm{s}$, translational velocity in the Y-direction (normal to the fence plane) $v_{y}=$ $16.7 \mathrm{~m} / \mathrm{s}$, and translational velocity in the Z-direction $v_{z}=2.3 \mathrm{~m} / \mathrm{s}$, which were obtained from the results in Test No. 2.

\subsection{Analysis, validation and discussion}

\subsubsection{Model No.1}

Generally, the numerical behavior of the fence did not match well that of the real fence, with some of the wire ropes breaking in the latter case. Therefore, the best value of the average friction force was obtained by iterative execution in which the magnitude of friction was increased until a good result was achieved. Eventually, it was found that the model with an average friction force of $85 \mathrm{kN}$ provided good results, as shown in Figs. 19 and 20, in which the fence was able to catch the block in spite of the breaking of wire ropes No. 6 and No. 7 and some damage to the wire netting. This numerical result matches the experimental result. Furthermore, Fig. 21 shows the Y-displacement of the central point of the impact area with time, and it is seen that the maximum displacement is close to that shown in Fig. 8 of Test No. 1.

It is thus asserted that numerical Model No. 1 can almost simulate Test No. 1 in terms of the overall behavior, the wire-rope breakage, and the deformation of posts, horizontal braces and vertical braces. There is however a considerable difference between the test and the numerical model in terms of the number of broken wire ropes; i.e., 7 vs. 2.

Figures 22 and 23 show the rope tension over time for each rope; the location of the ropes are indicated in Fig. 2. The figures present data calculated for the impact section and a section adjacent to an end post, respectively. It is clearly seen that rope Nos. 4 to 8, which passed through the contact area of the block and the fence, experienced greater tension in the impact section than in the section adjacent to the end post. However, the situation was the opposite for rope Nos. 1 to 3, which did not directly pass through the contact area. This phenomenon seems to come from the impact momentum being transferred from the contact area to the 
surrounding area via vertical braces and partly wire netting along a direction not perpendicular to the ropes.

Figure 24 shows the rope tension history measured in the section adjacent to the end post in Test No. 1. The method for measuring the rope tension from the strain at the U-bolt of an energy absorber is mentioned in Section 2.2. Although the peak values of tension for rope Nos. 1 to 7 were well under the tensile strength of 180 $\mathrm{kN}$, all these ropes broke in the impact section in the test. According to the numerical results illustrated in Figs. 22 and 23, in the impact section in Test No. 1, the peak values of tension for rope Nos. 1 to 7 certainly reached the tensile strength and resulted in their breaking.

\subsubsection{Model No.2}

Owing to the flexibility of the fence and the effectiveness of the Type-B energy absorbers, the amount of dissipated impact energy increased considerably, resulted in no breakage of the wire ropes, only little damage to the wire netting, and great effectiveness in catching the RC block. In particular, there is good agreement between experiment and numerical simulation in terms of the general track of the RC block during collision and the deformation of the fence. In both simulation and experiment, the block rebounded after being stopped by the fence. Figure 25 depicts the movement history of the block’s center in the Z-direction. Figure 26 shows the displacement history of the center of the contact area in the Y-direction. Figure 27 is the composite picture of an animation of Model No. 2. According to above points, it is obvious that the numerical simulation behavior of Model No. 2 agrees well with responses of the fence in Test No. 2.

Next, it is essential to analyze rope tension results for Model No. 2 and Test No. 2. There is a clear difference between Figs. 28 and 29, respectively showing the rope tensions calculated in the impact section and the section adjacent to the end post in Model No. 2; i.e., the rope tension was not constant along the rope line and varied considerably and the reason of this phenomenon is going to discuss at the end part of this section. Figure 29 shows that the magnitude of rope tension remained constant at approximately $45 \mathrm{kN}$ during the collision; i.e., the behavior of the energy absorber model was as prediction of the authors in Section 5.2. Figure 30 illustrates the severe fluctuation of rope tensions in the section adjacent to the end post in Test No. 2, and tensions of rope Nos. 2 to 4 indeed seem to 
exceed the tensile strength of $180 \mathrm{kN}$ but there was no breakage in Test No. 2 . This discrepancy unfortunately arises from unreliable measurement of rope tensions using the mismatched cross-sectional size of U-bolts of absorbers, since real rope tensions probably exceeded the yield capacity of the U-bolt of $135 \mathrm{kN}$ and therefore reached the region where the rope tension and U-bolt strain are not proportional. According to the experimental and numerical results, the energy absorber of Type B is functionally effective. Permitting wire rope to slide through a Type-B energy absorber not only dissipated the impact energy well but also prevented wire rope from breaking.

Figure 31 shows the impact force history of the colliding block in Test No. 2 and Model No. 2. There are obvious differences in the shape and timing of the peak value between the two curves. However, there is good agreement between the experiment and numerical analysis in terms of impulse (i.e., the time integration of the impact force) and time duration of the impact. These results demonstrate that Model No. 2 is a relevant simulation.

Figure 32 shows the tension of rope No. 5 measured at points P1 and P2 shown in Fig. 18. To examine the effects of friction between wire rope and vertical braces or intermediate posts, the friction coefficient for the contact condition in LSDYNA was changed as 0.3, 0.2, 0.1 and 0.01 in Fig. 32a, 32b, 32c and 32d, respectively. The figure shows that (1) the rope tensions measured at P1 and P2 points were remarkably dissimilar and (2) the amplitude of the variation in rope tension along the rope line declined with a decrease in the friction coefficient. Furthermore, the rope tensions at points P1 and P2 were almost the same in the short initial period of the collision when deformation of the ropes was not great and the slipping of wire rope through an absorber has not occurred yet. However, when the ropes started slipping, the friction became available and obstructed the ropes' slipping, resulted in the raise of the rope tension in the impact section. Therefore, evaluating the rope tension in the impact section allows consideration of the critical state of the wire rope. Moreover, although the friction coefficient was almost equal to zero in Fig. 32(d), there was still a difference in rope tension between P1 and P2 along the rope line. Of course, not only the friction between wire rope and vertical braces or intermediate posts but also the rope vibration due to the colliding block having many sharp edges might affected the variation in rope tension. 


\subsection{Further numerical analysis}

It seems that the Type-B energy absorber has greater capacity for dissipating impact energy and is better able to prevent the breaking of wire ropes; however, it is difficult to carry out additional experiments to confirm this. Numerical Model No. 2 was used in further numerical analysis with the aim of gaining a deeper understanding of the structural behavior of the rock fence. A parametric study was then executed.

\subsubsection{Further Examination of the Wire Netting and Posts}

Since the damage to the wire netting was mild in both Test No. 2 and Model No. 2 , the second layer of wire netting seems to be somewhat redundant. To verify this point, two different versions of Model No. 2 were created with one layer of wire netting having a $50 \times 50$-cell or $150 \times 150$-cell grid. Numerical results indicated that the rock fence can capture the RC-block in both cases, though the damage to wire netting was more severe in the latter case than in the former case. This consideration should be taken into account in constructing practical rock fences. Next, it is crucial whether the intermediate post would be able to sustain a direct hit by a RC-block, because this point has not been discussed in either the fullscale tests or the simulation on the rock fence. Another simulation of the impact at two-thirds height of the intermediate post in Model No. 2 was executed to verify the behavior of the post under the direct impact. Figure 33 shows that the post was entirely able to withstand the direct hit of the RC-block, which rolled up but did not bounce over the fence. Although local damage to a beam element under direct impact cannot be considered, this simulation result appears to be reliable because a post of concrete-filled tubular (CFT) steel is deformable and can resist a local direct hit (Maegawa et al. 1994).

\subsubsection{Energy Absorption Capacity of the Rock Fence}

The energy absorption capacity of a rock fence is defined as the maximum kinetic energy of rockfall that the rock fence can capture.

To determine the energy absorption capacity of the fence, all parameters of Model No. 2 were left unaltered, except for the magnitudes of the rotation and translation velocities. Many simulation analyses had been carried out by gradually increasing the impact energy with arithmetic progression of $50 \mathrm{~kJ}$ through various 
combinations of the two component velocities until the fence failed to capture the RC block; i.e., the block bounced over the fence without breaking the wire ropes because of the effectiveness of the absorbers. In these analyses, ratios of rotational energy to impact energy from $10 \%$ to $20 \%$ were examined according to the expected value in the practical design. Eventually, the highest energy for which the fence was able to catch the RC block was determined to be the energy absorption capacity of the fence. However, the highest energy firmly depends on a critical value of rotation velocity; i.e.,, when the rotation velocity exceeds this critical value, the RC-block bounces over the fence. The lower the critical rotation velocity, the higher the energy absorption capacity, as shown in Table 5. Only in the case of impact energy of $926 \mathrm{~kJ}$ is the magnitude of the rotation velocity not critical for the fence to catch the block. To further clarify this behavior of the fence, two composite animations are shown in Figs. 34 and 35, which respectively were obtained for Model No. 2 under impact energy of $1000 \mathrm{~kJ}$ with rotation velocities of 16 and $18 \mathrm{rad} / \mathrm{s}$. These figures show that the fence could capture the block having rotation and translation velocities of $16 \mathrm{rad} / \mathrm{s}$ and $17.8 \mathrm{~m} / \mathrm{s}$ but not the block having rotation and translation velocities of $18 \mathrm{rad} / \mathrm{s}$ and $17.3 \mathrm{~m} / \mathrm{s}$. This result suggests that the magnitude of the rotational velocity should be considered in designing this type of fence.

Table 5: Critical rotation velocity for typical impact energy levels

\begin{tabular}{|c|c|c|}
\hline $\begin{array}{l}\text { Impact Energy } \\
E(\mathrm{~kJ})\end{array}$ & $\begin{array}{l}\text { Critical Rotation } \\
\text { Velocity } \omega(\text { rad./s) }\end{array}$ & $\begin{array}{l}\text { Ratio of Rotational } \\
\text { Energy } \quad E r / E(\%)\end{array}$ \\
\hline 926 & Not available & 17.5 \\
\hline 1000 & 16 & 12.7 \\
\hline 1050 & 14 & 10.5 \\
\hline 1100 & 13 & \\
\hline
\end{tabular}

Next, to survey the effect of the location of the collision point on the energy absorption capacity of the rock fence, several models were created by varying the impact position. These impact positions are indicated by the letters "A" to "F" in Fig. 36. Table 6 shows that the resistance of the fence, not being uniform, strongly depends on the impact location. The ratio of rotational energy was more than the 10\% recommended by the Rockfall Mitigation Handbook (Japan Road Association 2006) in all cases, except in the case of position A, for which the 
magnitude of rotational velocity did not affect the energy absorption capacity of the fence. The most noticeable point here is that the impact energy absorption capacity of the fence was greater for impacts closer to the intermediate posts. For instance, the resistance of the fence corresponding to impact points B and D was higher than that for points A and C. Moreover, these results match well with those obtained by Cazzani (A Cazzani et al. 2002). In addition, the resistance of the fence was seriously reduced for higher impact points on the wire mesh such as points $\mathrm{C}$ and $\mathrm{D}$. However, the situation was the opposite for impact locations on the intermediate posts, in that an impact near the post base was more critical. This suggests that thorough consideration of the impact position is crucial in determining the energy absorption capacity of the fence.

Table 6: Energy absorption capacity of the rock fence according to six different points of impact

\begin{tabular}{|l|c|c|c|}
\hline $\begin{array}{l}\text { Impact } \\
\text { Location }\end{array}$ & $\begin{array}{l}\text { Energy Absorption } \\
\text { Capacity } \quad E(\mathrm{~kJ})\end{array}$ & $\begin{array}{c}\text { Critical Rotation } \\
\text { Velocity } \omega(\text { rad./s) }\end{array}$ & $\begin{array}{c}\text { Ratio of Rotational } \\
\text { Energy } \quad E r / E(\%)\end{array}$ \\
\hline Position A & 1400 & Not available & 15.9 \\
\hline Position B & 1550 & 19 & 15.1 \\
\hline Position C & 450 & 10 & 14 \\
\hline Position D & 700 & 12 & 14.9 \\
\hline Position E & 900 & 14 & 15.7 \\
\hline Position F & 850 & 14 & \\
\hline
\end{tabular}

\section{Conclusion}

This paper presented experimental results for a newly developed rock fence able to vertically stand by itself without lateral guy cables and anchors. The fence was subjected to impact by an RC block rolling down a natural steep slope. The acceleration or impact force of the RC block colliding with the fence was measured with a measurement control system that was able to synchronize all measuring instruments. The impact energy approximately estimated in two fullscale tests (having different shock absorbers) was about $900 \mathrm{~kJ}$, which is lower than that expected for the site conditions (Japan Road Association 2006). However, the rotational energy was $17 \%$ to $20 \%$ of the total impact energy, which is more than the value of $10 \%$ recommended by the Rockfall Mitigation Handbook (Japan Road Association 2006). Despite the higher rotational energy, the RC block did not bounce over the fence in either test because of the flexibility 
of the fence structure. More importantly, the residual deformation of the fence after impact was about $1000 \mathrm{~mm}$, making the fence suitable to be installed just aside roads, where very little space exists.

Two types of energy absorber examined in laboratory pre-tests were assembled for the rock fences in the full-scale tests to confirm their energy-dissipation functions. The Type-B energy-absorbing device was found to be effective in preventing wire-rope breakage and in dissipating the impact energy of rockfall and it thus considerably enhanced the impact energy absorption capacity of the fence.

Additionally, numerical simulation using the finite element code LS-DYNA was performed to model the rockfall collision in both Tests No. 1 and No. 2.

Generally, the numerical results agree fairly well with the experimental results in terms of deformation of the whole fence, the structural behavior of each component, and the acceleration or impact force of the RC block. Furthermore, they provide further insight into the responses of individual components and the fence as a whole, particularly the effect of friction between wire ropes and intermediate posts or vertical braces on the distribution of rope tension along the rope line. Further numerical simulation has provided valuable information relating to the intensive ductility of the posts and structural behavior of wire netting under rockfall impact, leading to the possibility of reducing the wire netting from two layers to one layer or even one coarser layer with a grid of $150 \times 150$ cells, which would reduce costs. A thorough examination of how the position of the collision point affects the performance of the rock fence showed that the resistance of the fence greatly depends on the impact location. The energy absorption capacity of the fence was greater for impact locations closer to the intermediate posts but seriously decreased for impact points above two thirds of the fence height. The numerical results also indicated that the magnitude of the rotational velocity of the block is an important factor determining whether the fence can catch the block in various cases of impact position. This suggests that the overall flexibility of the fence is not always sufficient to catch a block regardless of the rotational velocity. However, the ratio of the critical rotational energy for most of specific impact locations was much higher than $10 \%$, which is the value frequently used in practice and recommended by the Rockfall Mitigation Handbook (Japan Road Association 2006). 
As a final remark, it should be emphasized that the integration of full-scale tests and numerical simulation is crucial to the inspection and verification of a rock fence subjected to rockfall. First, experimental results obtained from full-scale tests provide a primary understanding of the overall performance of the fence, and in particular, they are necessary to validate adopted numerical models. Dynamic finite element analyses can then provide new insight into the response of the rock fence through iterative executions. Last but not least, numerical simulation is suitable in any parametric study and is therefore useful for designing purpose.

\section{Acknowledgements}

Experiments were carried out in cooperation with the High-Power Rock Fence Association, and the authors wish to express their gratitude to all members of the association for their close collaboration. The authors appreciate the great efforts made by anonymous reviewers in providing suggestions that considerably improved the paper.

\section{References}

A Cazzani, L Mongiovì, T. F. (2002) Dynamic finite element analysis of interceptive devices for falling rocks. International Journal of Rock Mechanics and Mining Sciences 39(3): 303-321

ETAG-027 (2008) Guideline for European Technical Approval of Falling Rock Protection Kits. European Organization for Technical Approvals (EOTA)

Grillo F, Rega G, Vestroni F (1985) Ultimate resistance of structural steel elements for impulsive loads. Costruzioni Metalliche 37(4): 185-201

Japan Road Association (2006) Rockfall Mitigation Handbook

Kishi N, Konno H, Ikeda K, Matsuoka K G (2002) Prototype impact tests on ultimate impact resistance of PC rock-sheds. International Journal of Impact Engineering 27: 969-985

Lambert S, Gotteland P, Nicot F (2009) Experimental study of the impact response of geocells as components of rockfall protection embankments. Natural Hazards and Earth System Sciences 9: 459-467

Maegawa K (2006) Weight impact tests on a flexible polyethylene net rock fence. Proc. of the 3rd International Conference on Protection of Structures against Hazards 43-50

Maegawa K, Tomida M, Yoshida H (1994) Impulsive Loading Tests on Concrete-Filled Tubular Steel Beams Reinforced with Tendon. Proceeding of ASCCS-4 531-534

Maegawa K, Yoshida H (1995) Collision Tests on a New Type of Rock Barrier. Proceeding of EASEC-5 1927-1932

Maegawa K, Yokota T, Tran P V (2011) Experiments on Rockfall Protection Embankments with Geogrids and Cushions. International Journal of Geomate 19-24 
Pichler B, Hellmich C, Mang H (2005) Impact of rocks onto gravel Design and evaluation of experiments. International Journal of Impact Engineering 31(5): 559-578. doi:10.1016/j.ijimpeng.2004.01.007

Ronco C, Oggeri C, Peila D (2009) Design of reinforced ground embankments used for rockfall protection. Natural Hazards and Earth System Sciences 9(1993): 1189-1199

Fig. 1 Absorber -Type A(a) and Absorber-Type B(b)

Fig. 2 Configuration and dimensions of the rock fence

Fig. 3 Experimental control system

Fig. 4 Test diagram

Fig. 5 Laboratory test for an energy absorber

Fig. 6 Impulsive friction vs. rope elongation curve

Fig. 7 Collision point on the rock fence at mid-span

Fig. 8 Behavior of the rock fence (Test No. 1)

Fig. 9 Behavior of the rock fence (Test No. 2)

Fig. 10 Wire rope slippage for Test No.2

Fig. 11 Deceleration and impact force history (Test No. 1)

Fig. 12 Deceleration and impact force history (Test No. 2)

Fig. 13 Stress-strain curve derived from the steel-cable static tensile test

Fig. 14 Assumed stress-strain curve applied for wire ropes (a) and wire netting (b)

Fig. 15 Numerical model applied for energy absorber

Fig. 16 Assumed stress-strain curve (a) and simplified behavior of absorbers (b)

Fig. 17 Bending moment vs. deflection curve of posts (a) and assumed stress-strain curve of posts (b)

Fig. 18 Technical sketch of the wire-rope rock fence built in LS-DYNA

Fig. 19 A series of motions in Model No.1

Fig. 20 Damage to wire ropes No. 6 and No. 7 and wire netting

Fig. 21 Time vs. Y-displacement of center of impact area in Model No. 1

Fig. 22 Time vs. Rope tension at impact section in Model No. 1

Fig. 23 Time vs. Rope tension at section adjacent to an end post in Model No. 1

Fig. 24 Time vs. Rope tension at section adjacent to an end post in Test No. 1

Fig. 25 Time vs. Block movement in Z-direction in Model No. 2

Fig. 26 Y-displacement history of wire-mesh measured at center of contact area in Model No. 2

Fig. 27 Composite picture from animation in Model No. 2

Fig. 28 Time vs. Rope tension at impact section in Model No. 2

Fig. 29 Time vs. Rope tension at section adjacent to an end post in Model No. 2

Fig. 30 Time vs. Rope tension at section adjacent to an end post in Test No. 2

Fig. 31 Impact force of block in Model No.2 and Test No.2

Fig. 32 Rope tension of rope No.5 for corresponding friction coefficients 
Fig. 33 Composite picture from animation of intermediate post directly hit

Fig. 34 Composite picture in Model No. 2 under $E(1000 \mathrm{~kJ})$ and $\omega(16 \mathrm{rad} . / \mathrm{s})$

Fig. 35 Composite picture in Model No. 2 under $E(1000 \mathrm{~kJ})$ and $\omega(18 \mathrm{rad} . / \mathrm{s})$

Fig. 36 Map of impact locations 


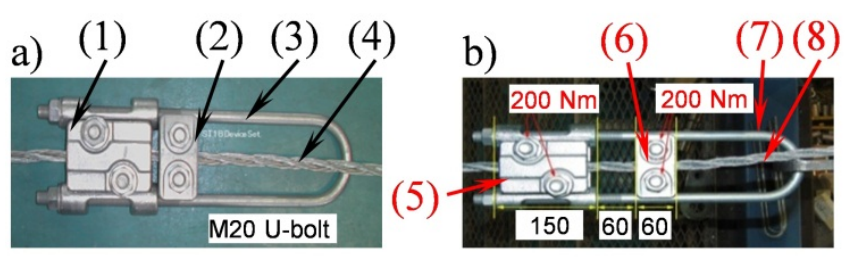

(1) \& (2) is fixed to (3) - (4) can slip through (1) \& (2) - (5) is fixed to (7) - (6) can initially move along (7) - (8) can slip through (5) \& (6).

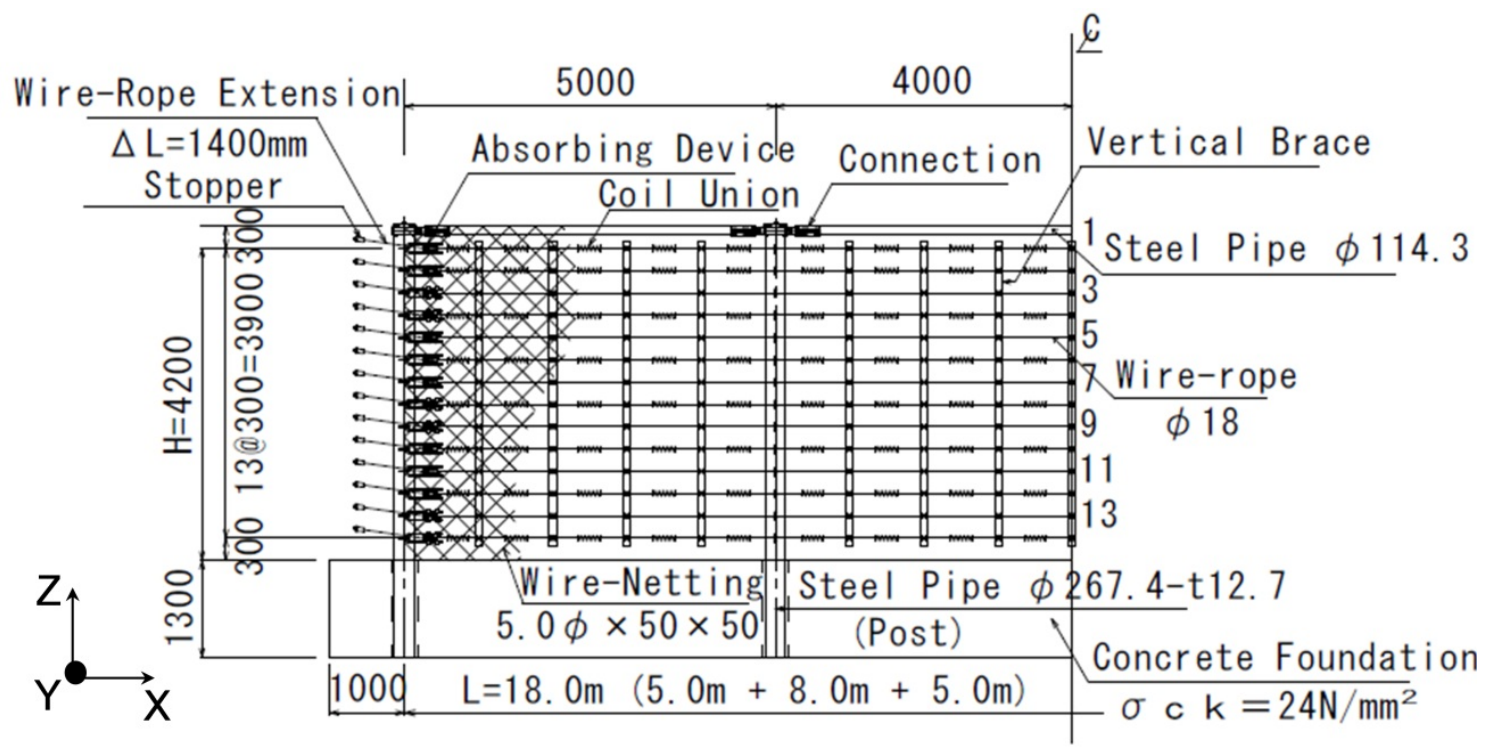

Fig. 2 Configuration and dimensions of the rock fence

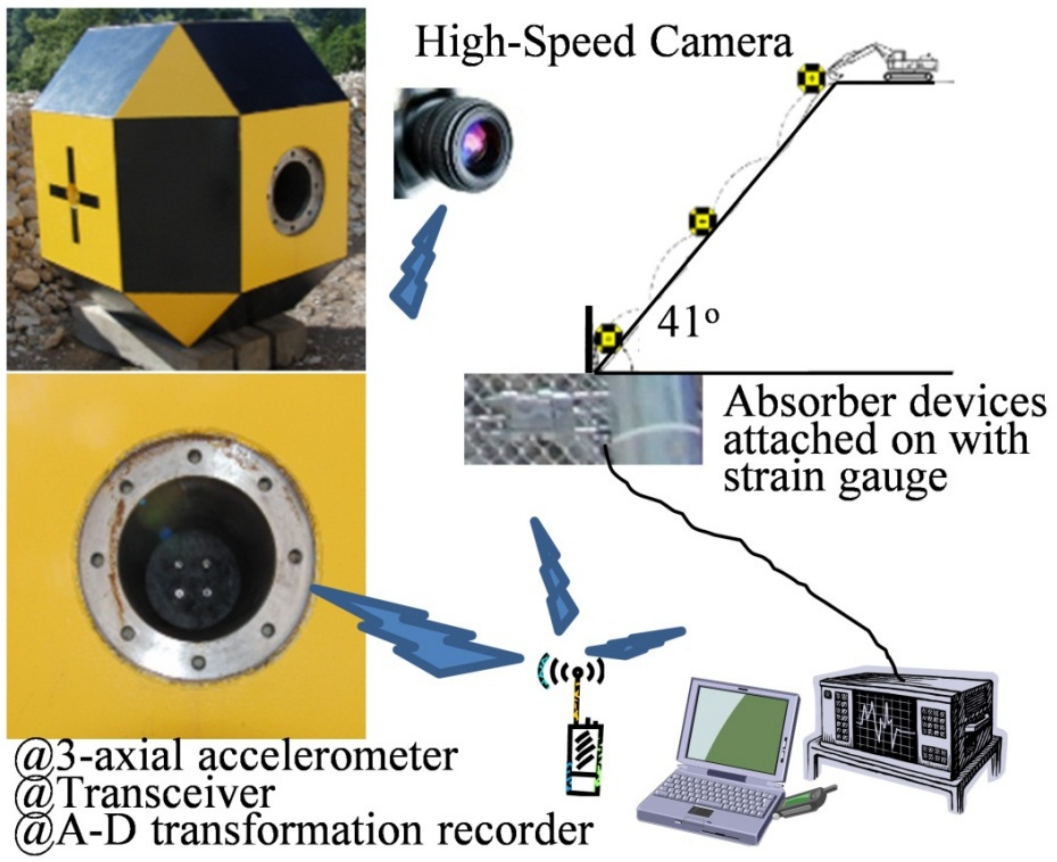

Fig. 3 Experimental control system 


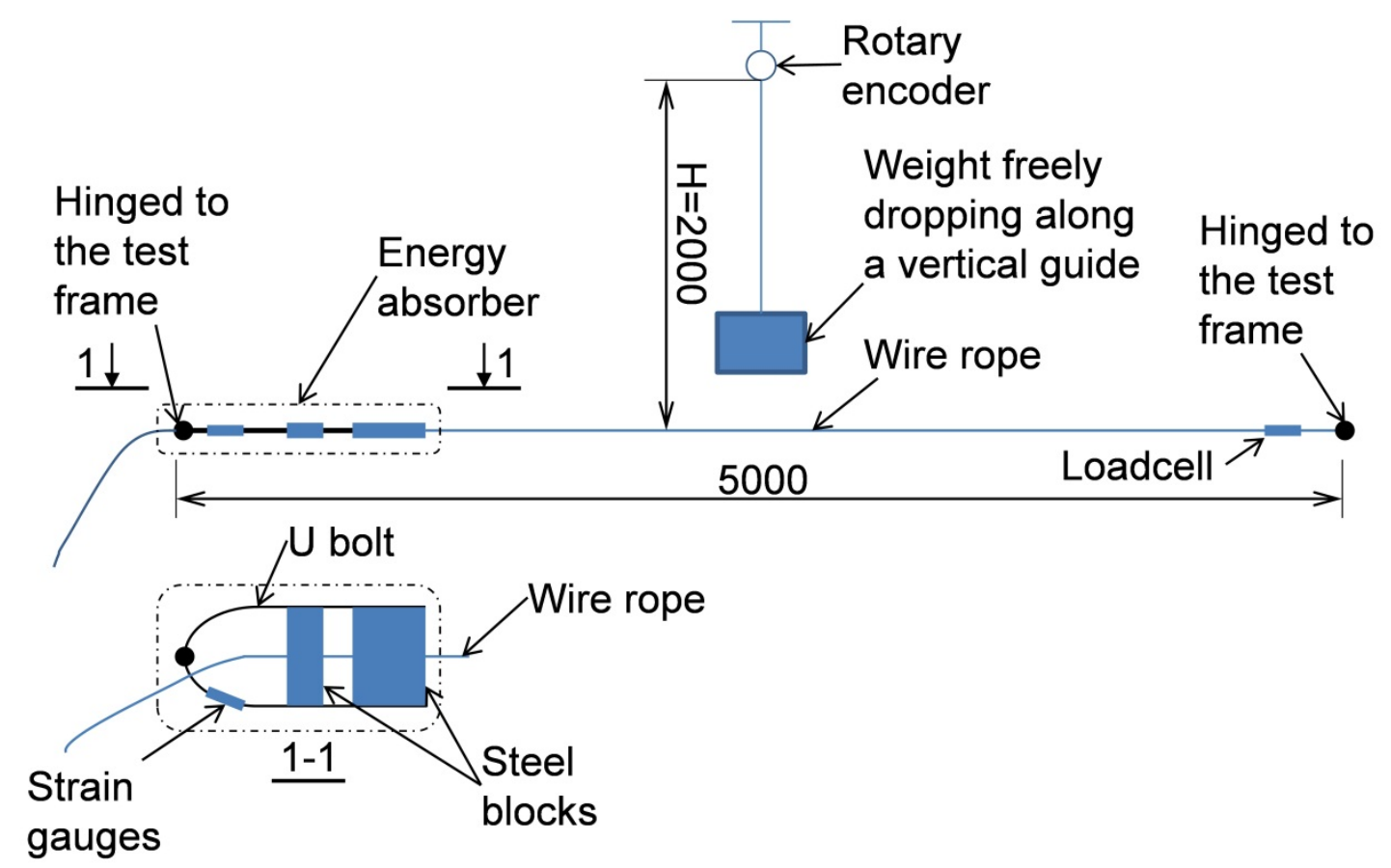

Fig. 4 Laboratory test for an energy absorber
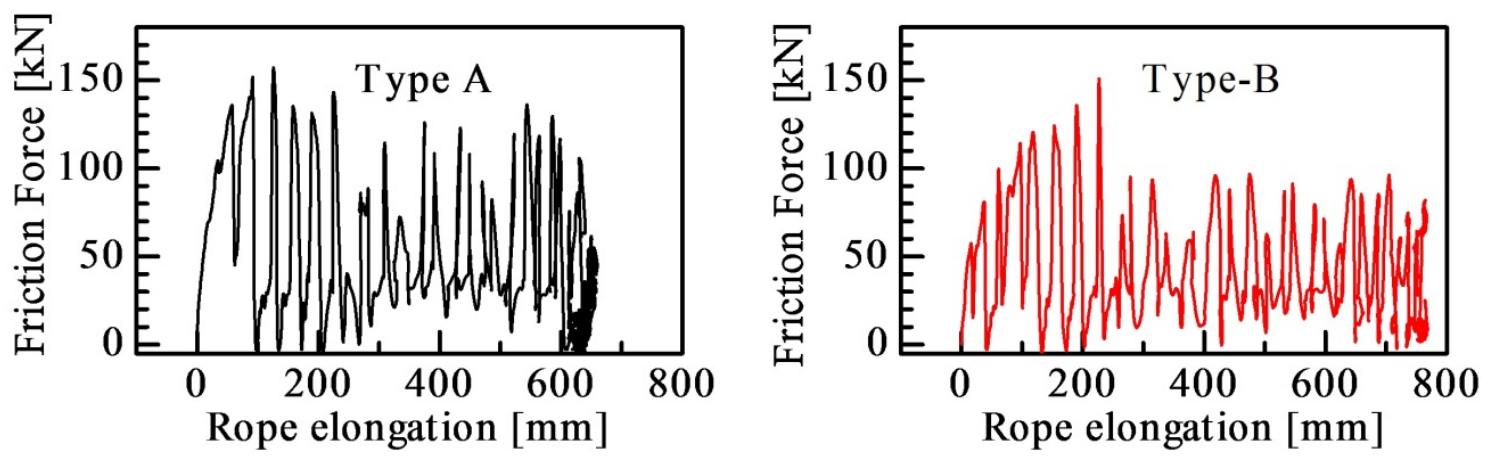

Fig. 5 Impulsive friction vs. rope elongation curve

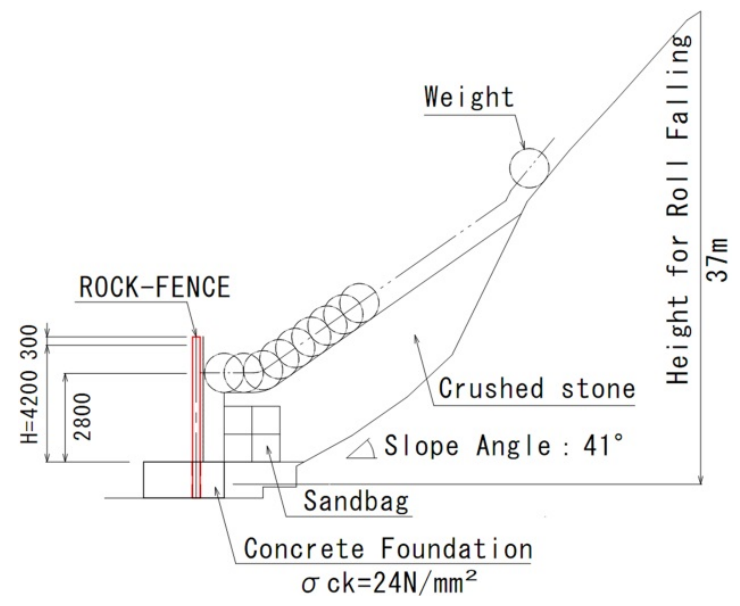

Fig. 6 Test diagram 


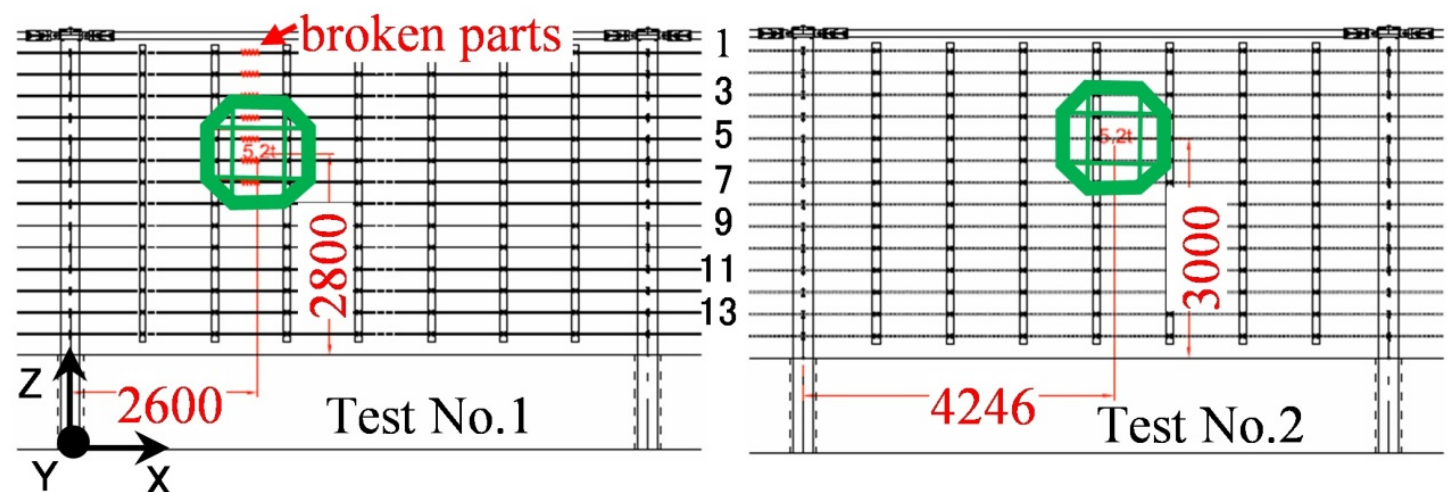

Fig. 7 Collision point on the rock fence at mid-span
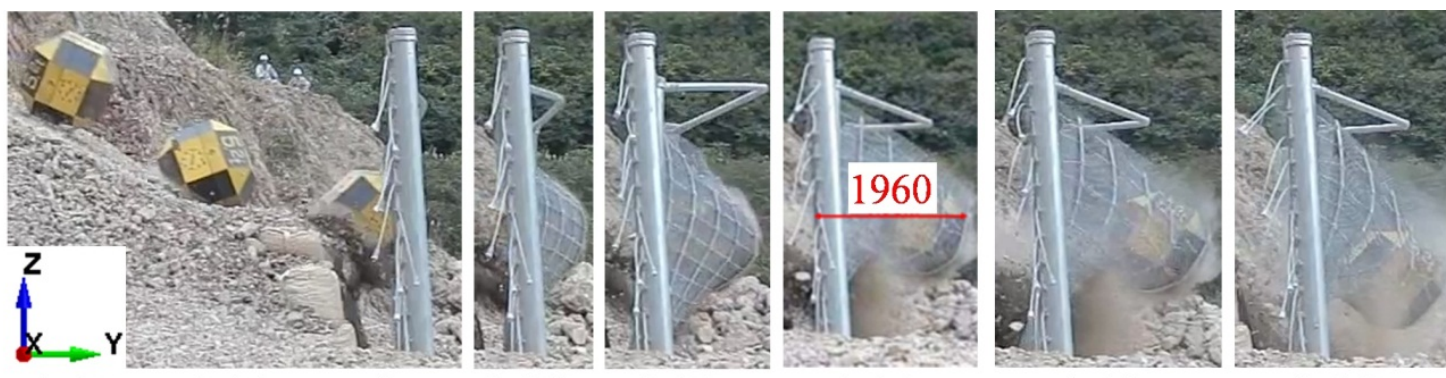

$-0.37 \mathrm{~s}-0.20 \mathrm{~s}$

$0.08 \mathrm{~s} \quad 0.20 \mathrm{~s}$

$0.38 \mathrm{~s}$

$0.49 \mathrm{~s}$

$0.99 \mathrm{~s}$

Fig. 8 Behavior of the rock fence (Test No. 1)
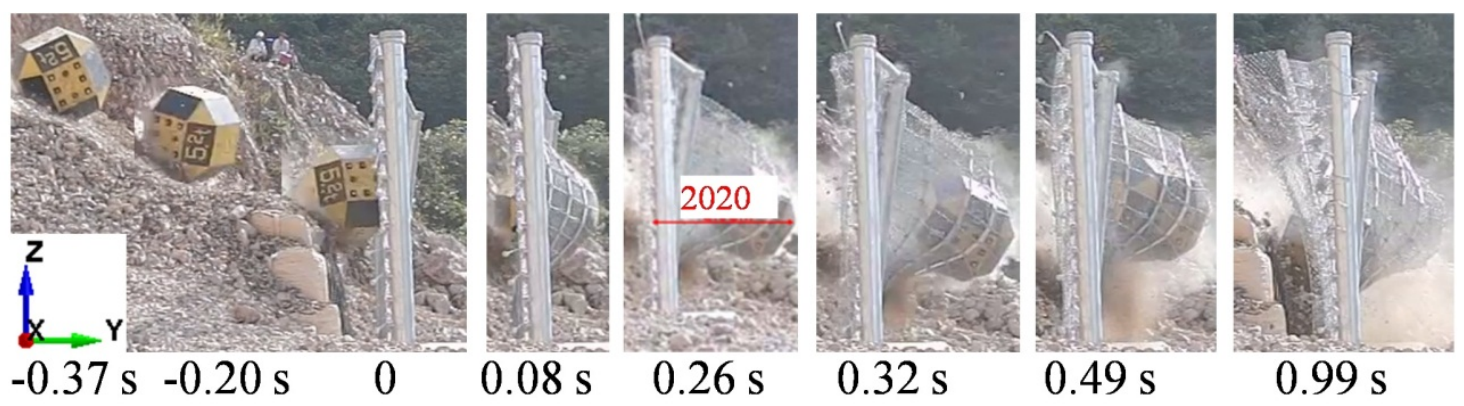

$0.32 \mathrm{~s}$

$0.49 \mathrm{~s}$

$0.99 \mathrm{~s}$

Fig. 9 Behavior of the rock fence (Test No. 2) 


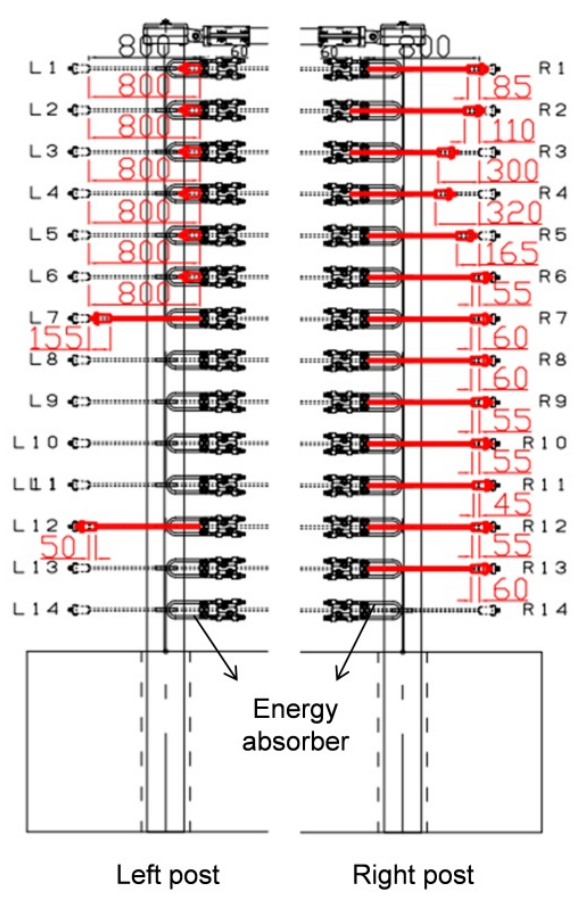

Fig. 10 Wire rope slippage for Test No.2

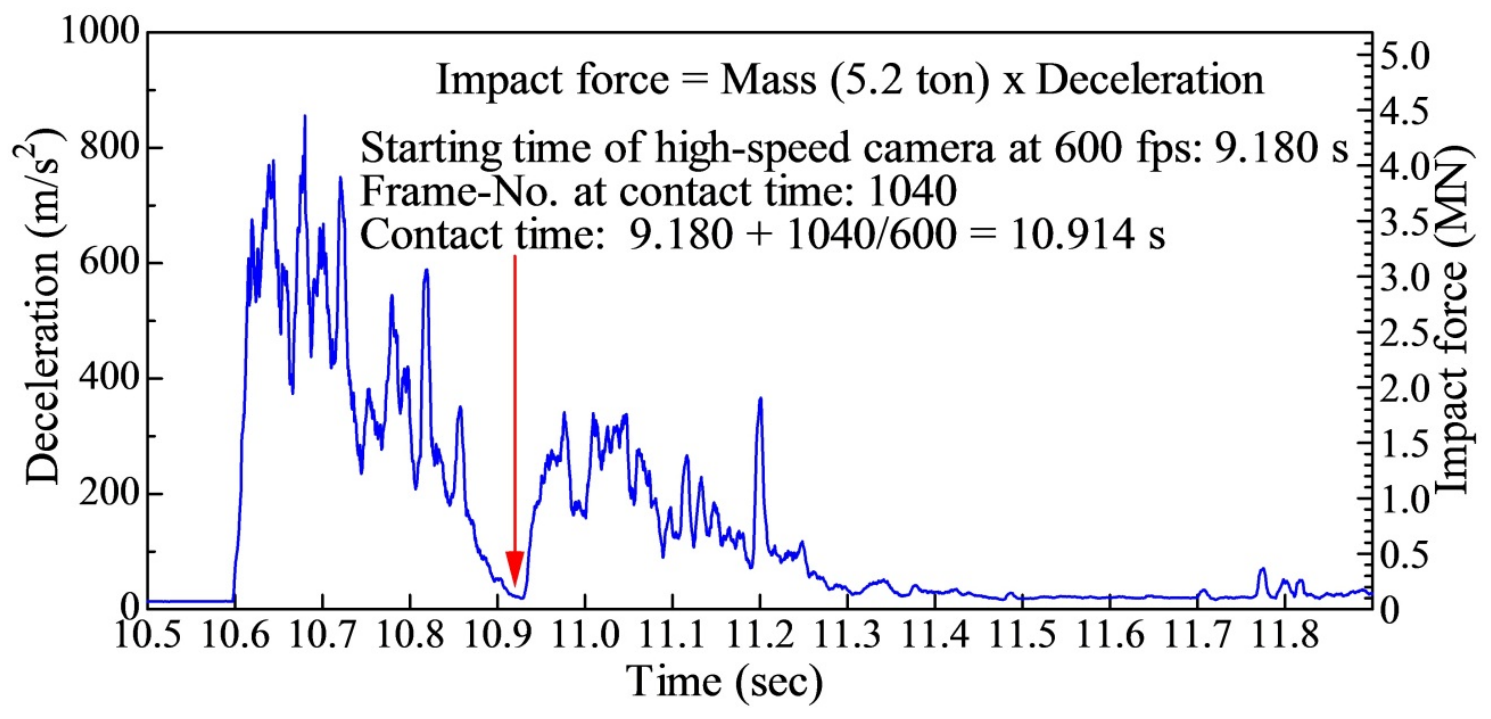

Fig. 11 Deceleration and impact force history (Test No. 1) 


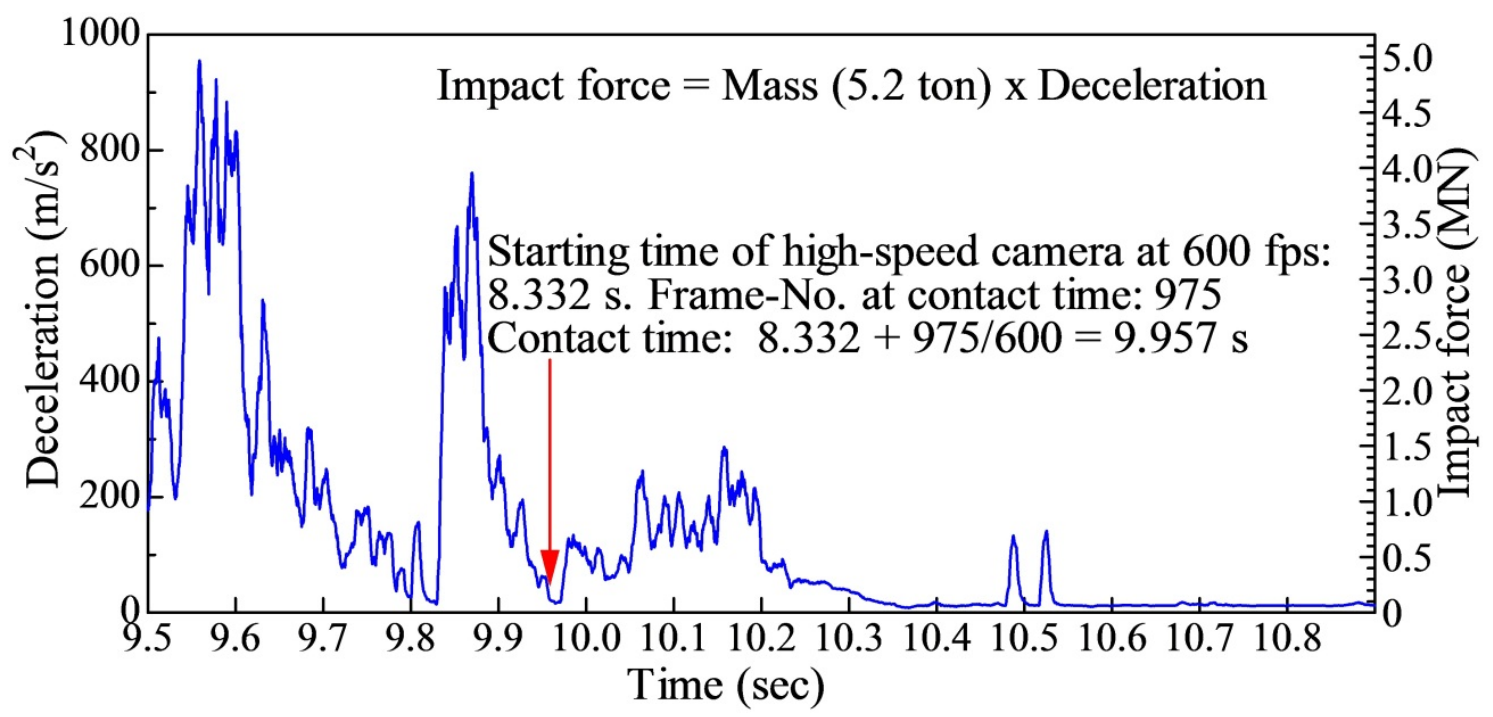

Fig. 12 Deceleration and impact force history (Test No. 2)

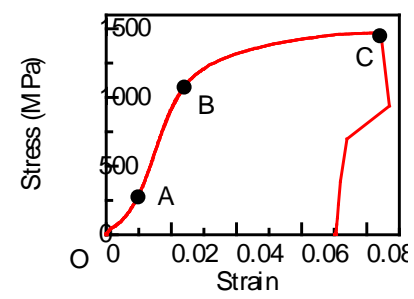

Fig. 13 Stress-strain curve derived from the steel-cable static tensile test
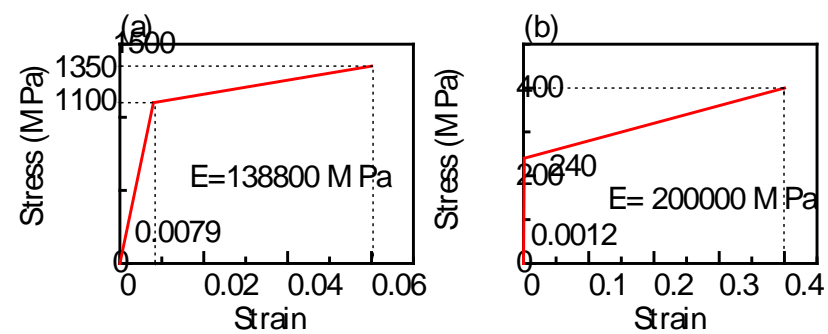

Fig. 14 Assumed stress-strain curve applied for wire ropes (a) and wire netting (b)

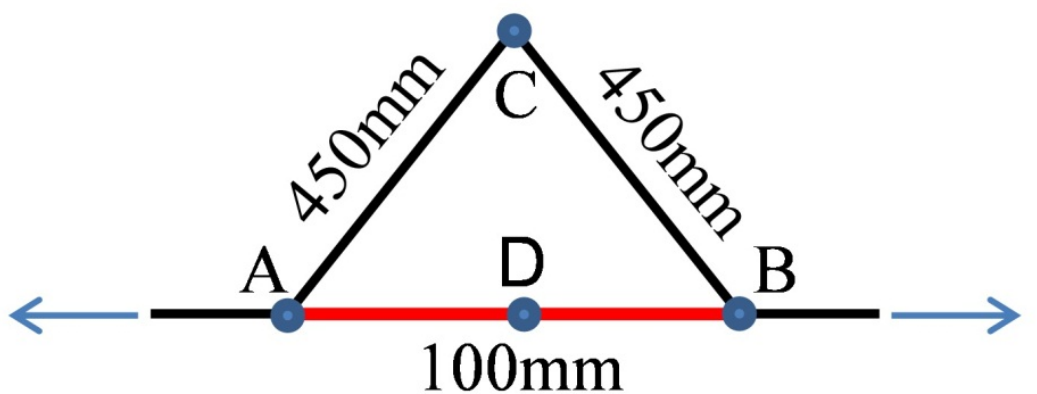

Fig. 15 Numerical model applied for energy absorber 

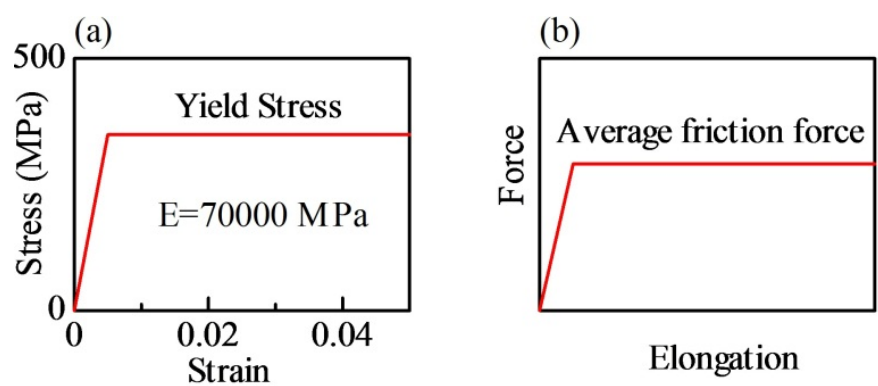

Fig. 16 Assumed stress-strain curve (a) and simplified behavior of absorbers (b)
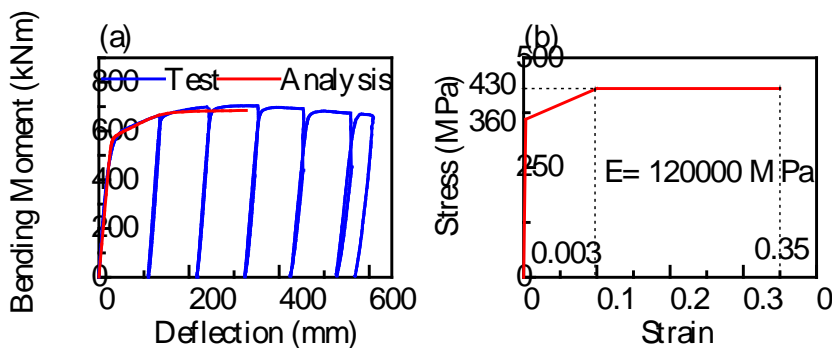

Fig. 17 Bending moment vs. deflection curve of posts (a) and assumed stress-strain curve of posts (b)

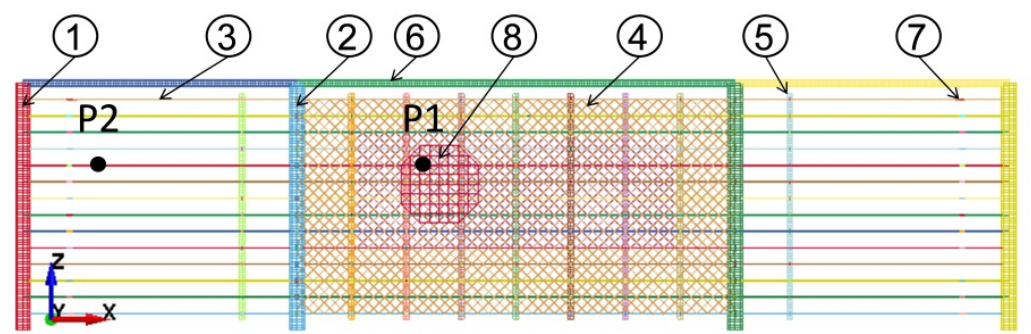
(1) End post
(5) Vertical brace
P1, P2 : Points
(2) Intermediate post
(3) Wire rope
6) Horizontal brace
of data analysis
(4) Wire netting
(7) Energy absorber
for numerical
(8) Colliding block
simulations

Fig. 18 Technical sketch of the wire-rope rock fence built in LS-DYNA
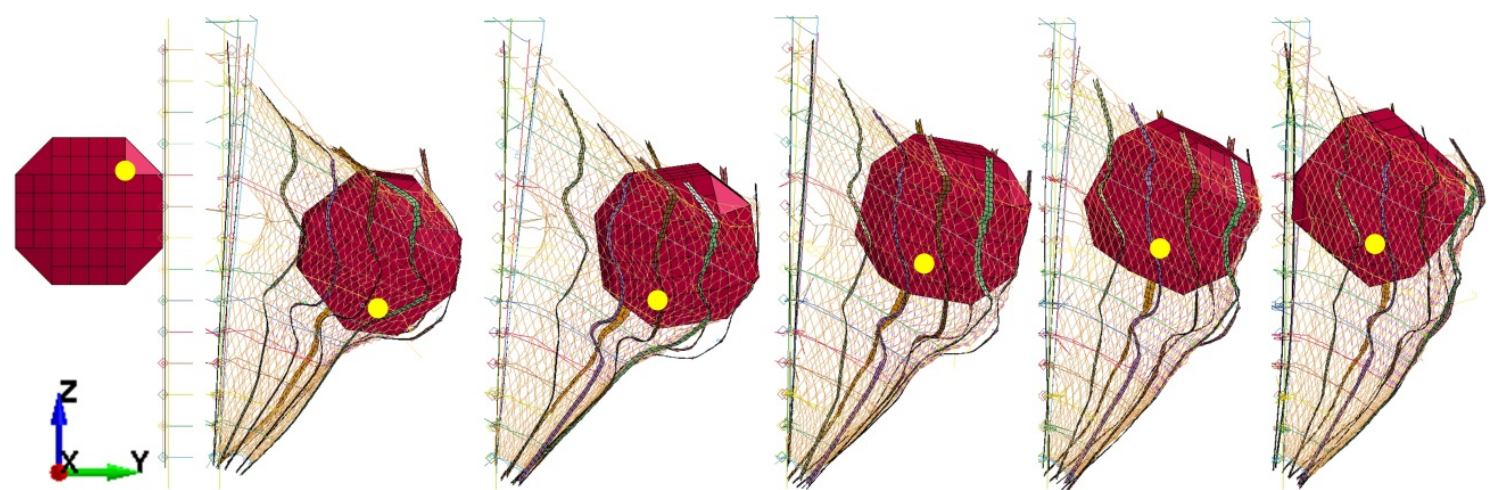

Os $\quad 0.2 \mathrm{~s}$

$0.3 \mathrm{~s}$

$0.4 \mathrm{~s}$

$0.5 \mathrm{~s}$

$0.6 \mathrm{~s}$

Fig. 19 A series of motions in Model No. 1 


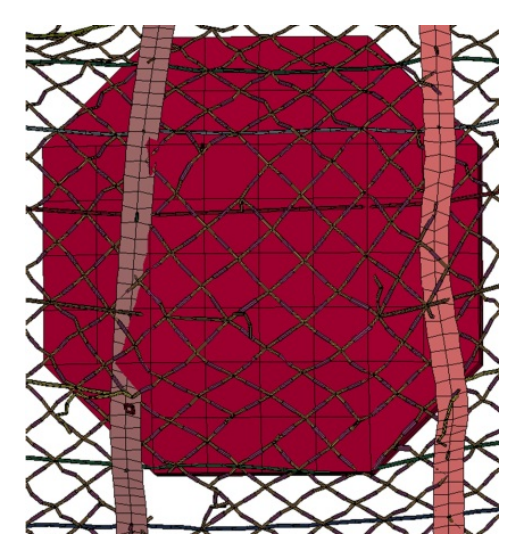

Fig. 20 Damage to wire ropes No. 6 and No. 7 and wire netting

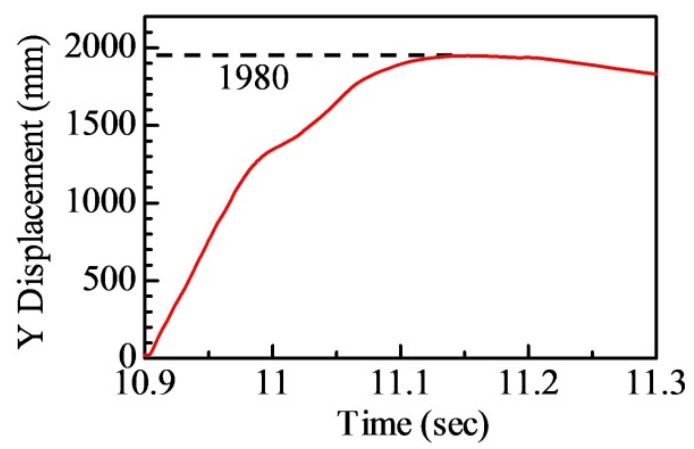

Fig. 21 Time vs. Y-displacement of center of impact area in Model No. 1
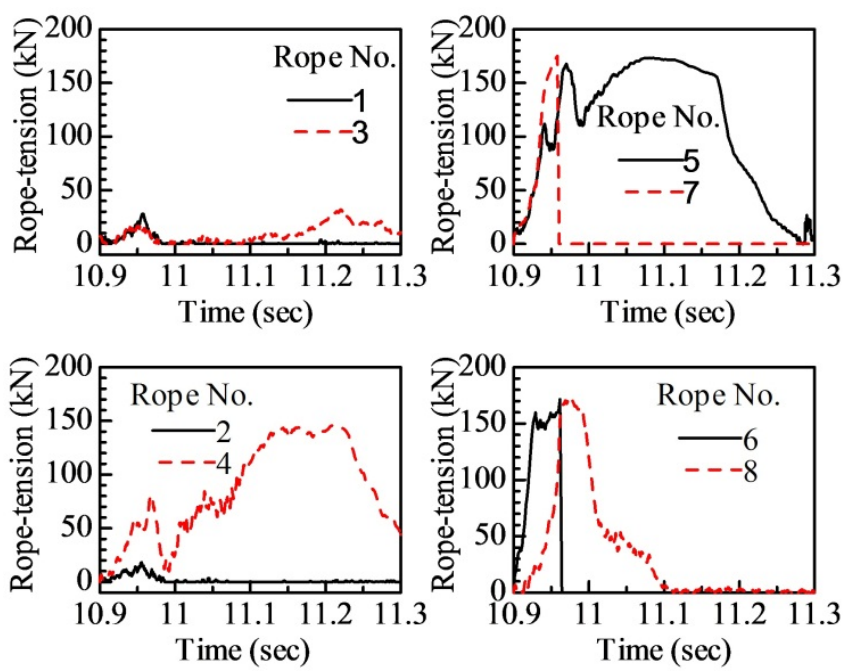

Fig. 22 Time vs. Rope tension at impact section in Model No. 1 

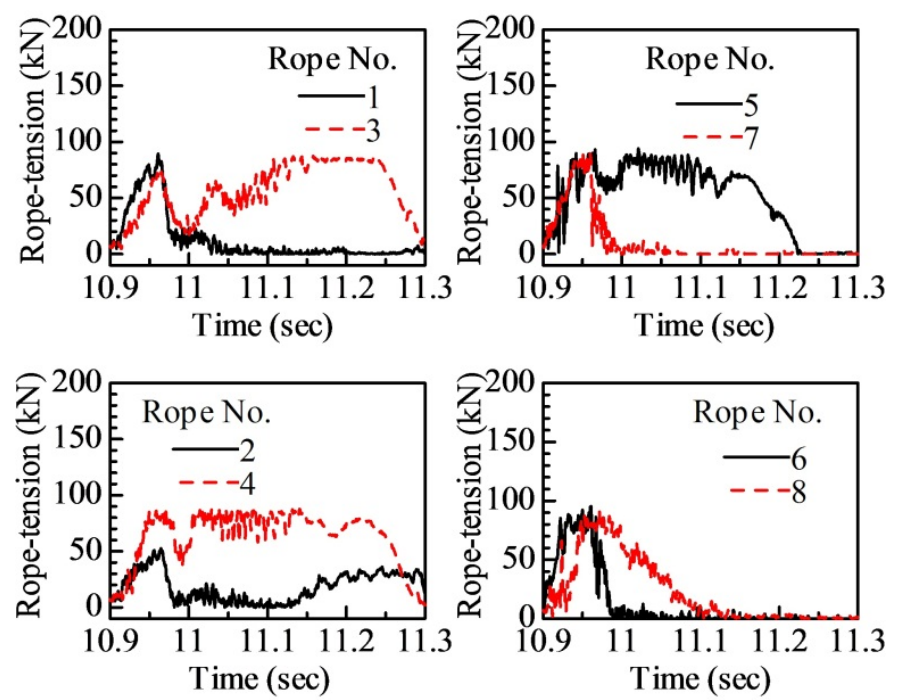

Fig. 23 Time vs. Rope tension at adjacent section next to end post in Model No. 1
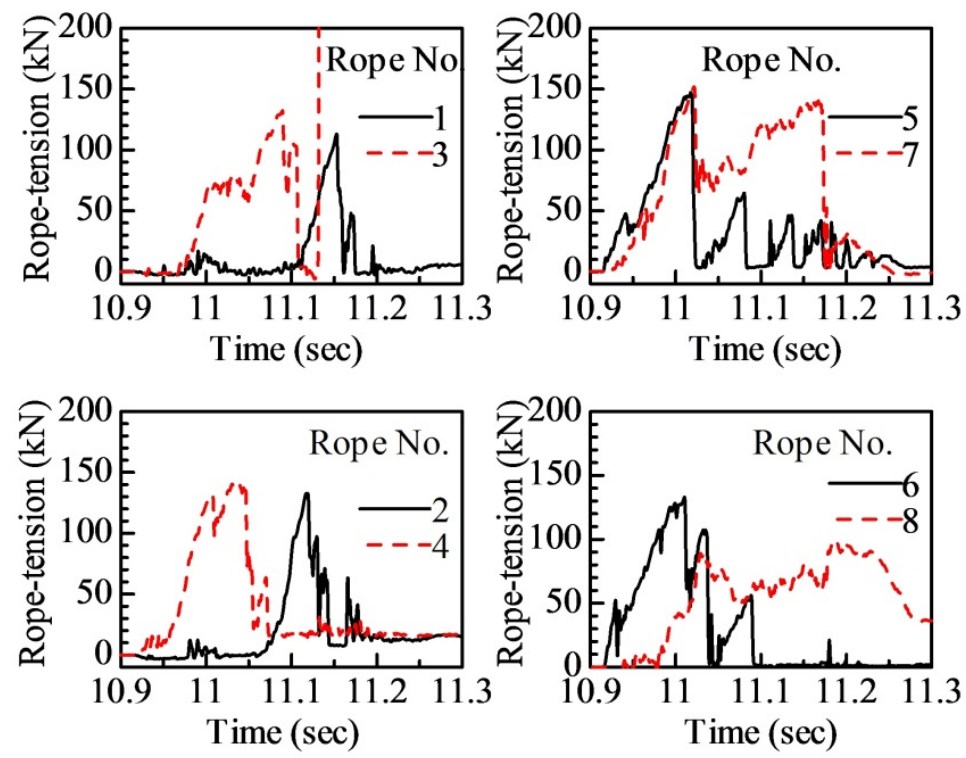

Fig. 24 Time vs. Rope tension at adjacent section next to end post in Test No. 1

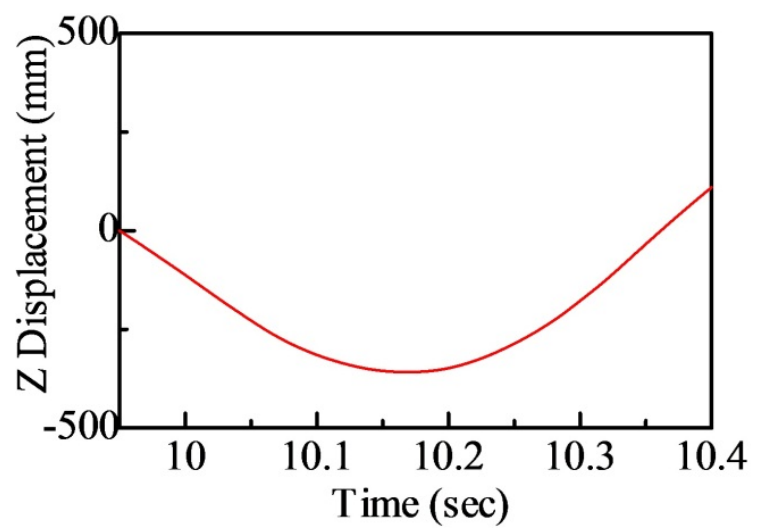

Fig. 25 Time vs. Block movement in Z-direction in Model No. 2 


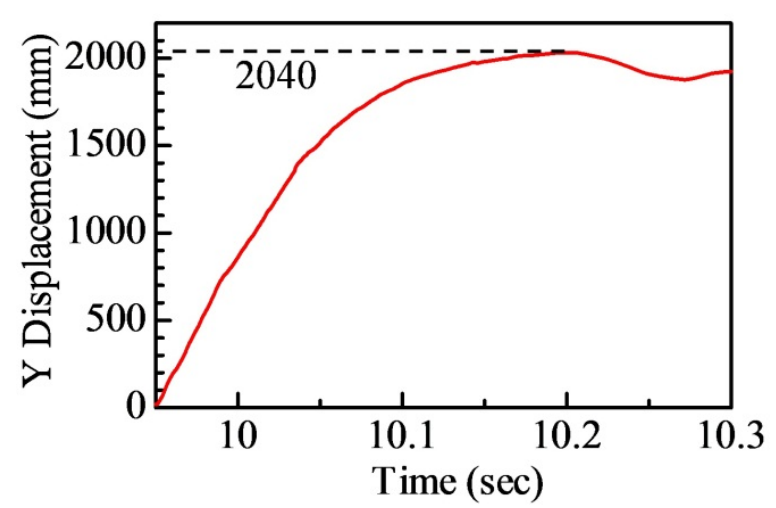

Fig. 26 Y-displacement history of wire-mesh center of contact area in Model No. 2

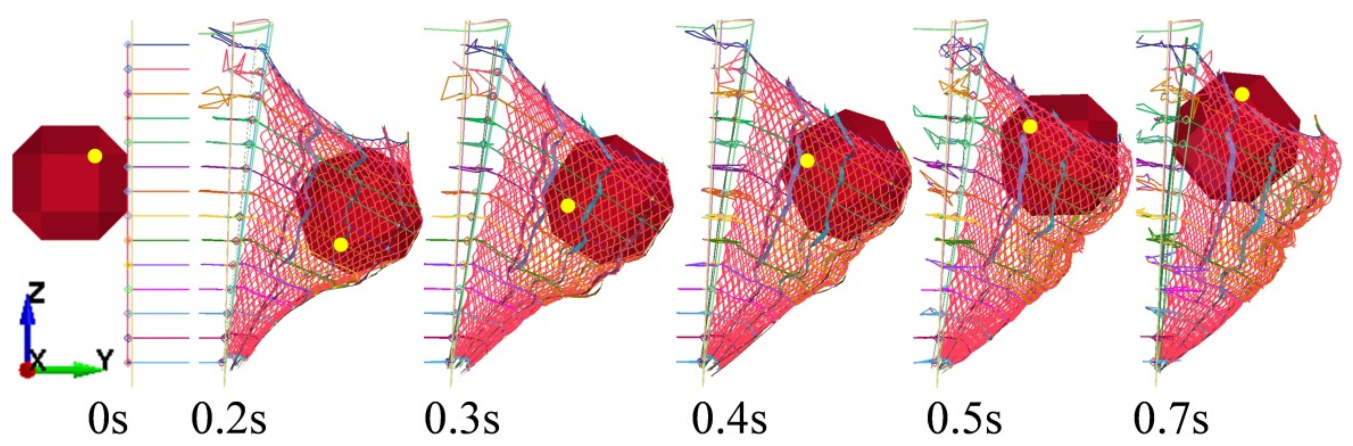

Fig. 27 Composite picture from animation in Model No. 2
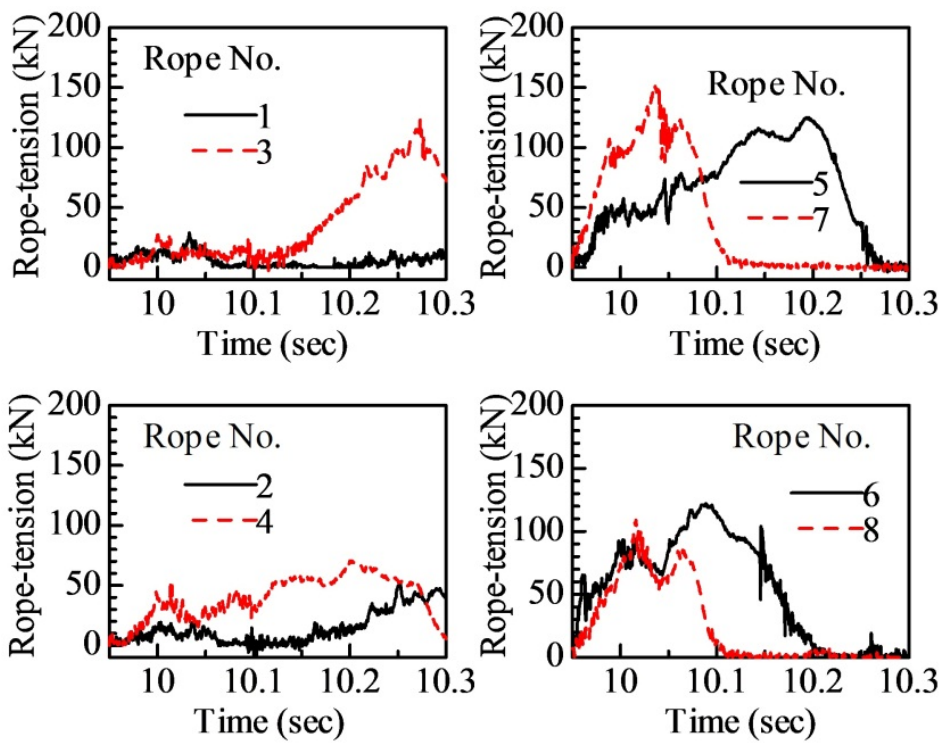

Fig. 28 Time vs. Rope tension at impact section in Model No. 2 

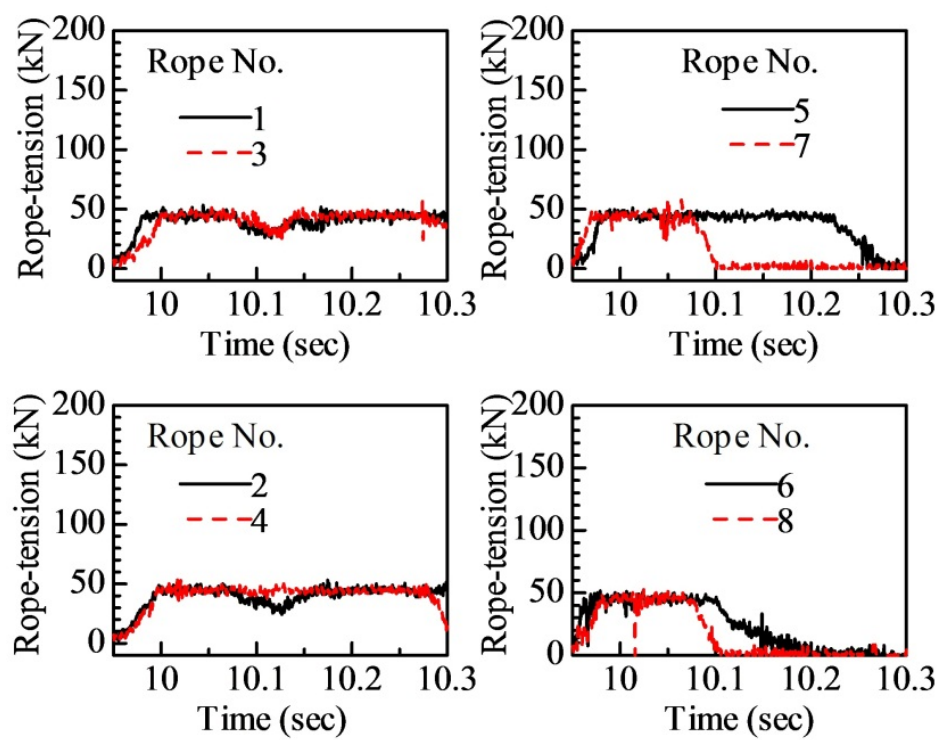

Fig. 29 Time vs. Rope tension at section next to an end post in Model No. 2
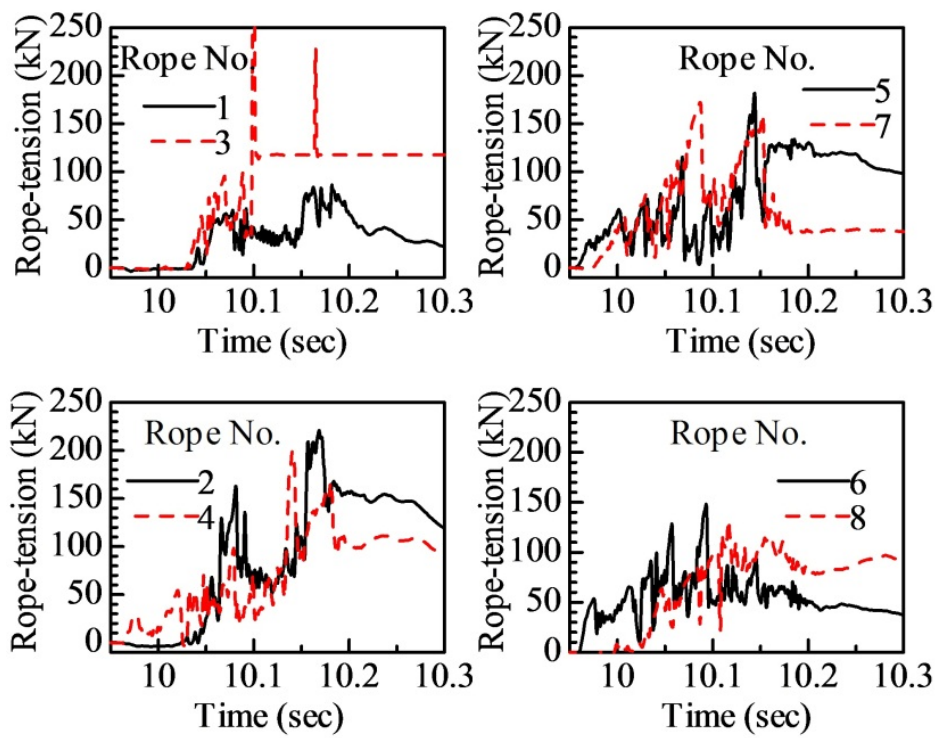

Fig. 30 Time vs. Rope tension at section next to an end post in Test No. 2

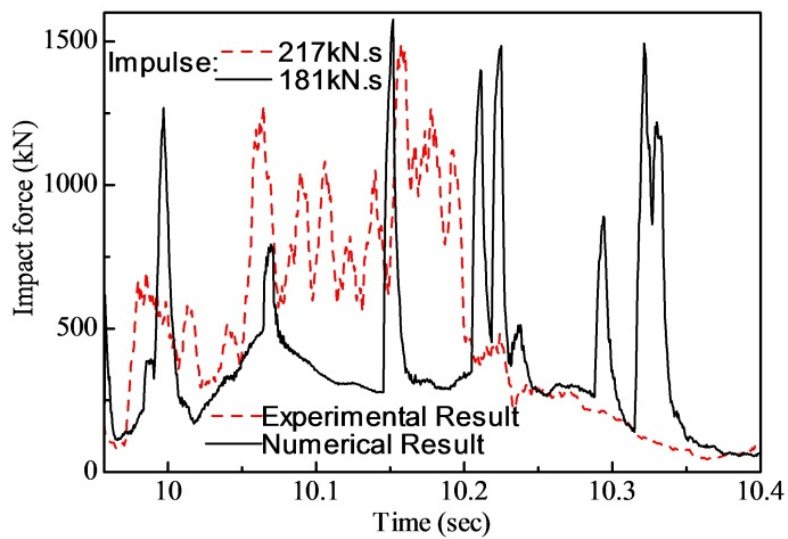

Fig. 31 Impact force of block in Model No. 2 and Test No. 2 

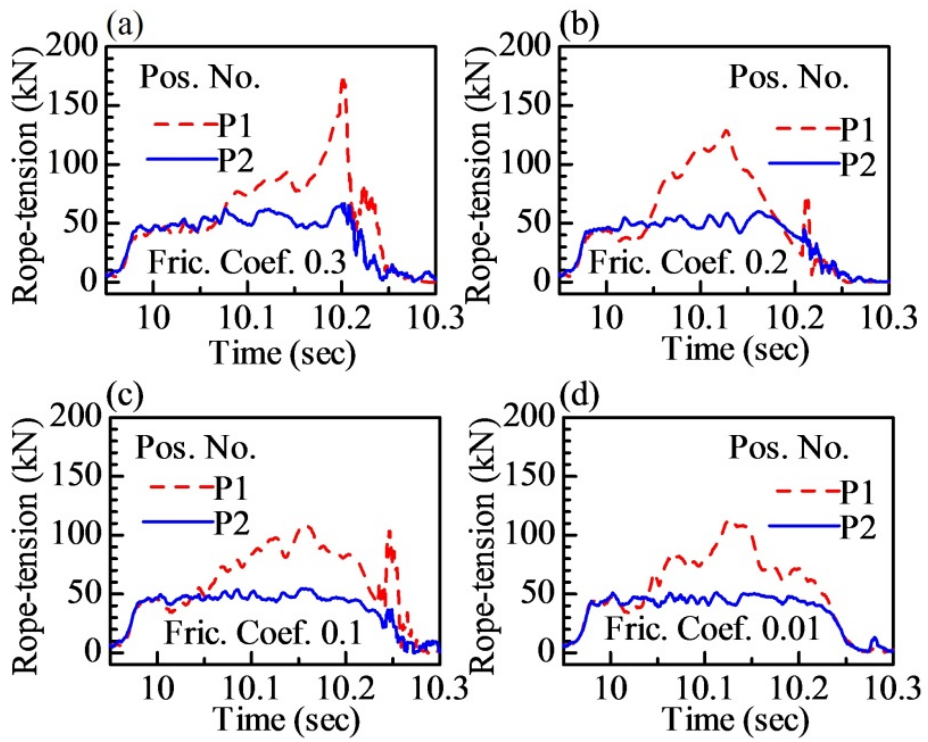

Fig. 32 Rope tension of rope No.5 for corresponding friction coefficients

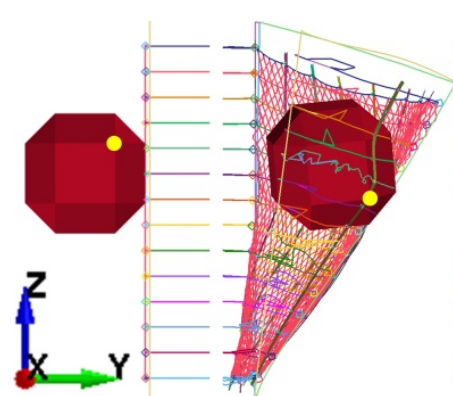

$0 \mathrm{~s}$

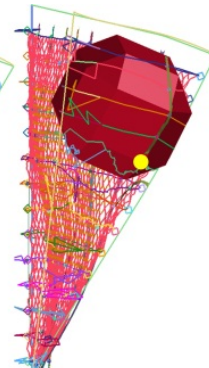

$0.32 \mathrm{~s}$

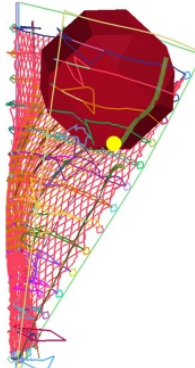

$0.4 \mathrm{~s}$

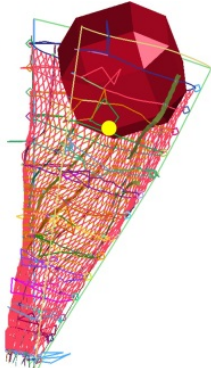

$0.5 \mathrm{~s}$

Fig. 33 Composite picture from animation of intermediate post directly hit

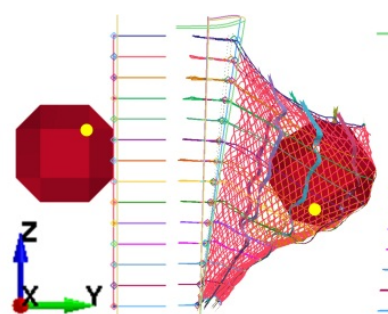

0s $\quad 0.20 \mathrm{~s}$

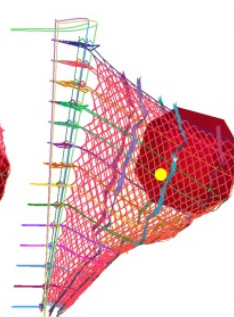

$0.32 \mathrm{~s}$

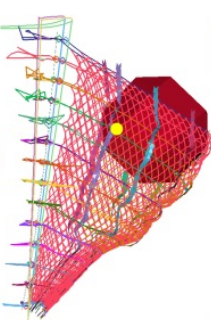

$0.45 \mathrm{~s}$

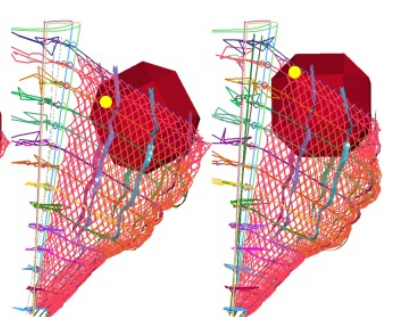

$0.55 \mathrm{~s}$

$0.70 \mathrm{~s}$

Fig. 34 Composite picture in Model No. 2 under $E(1000 \mathrm{~kJ})$ and $\omega(16 \mathrm{rad} . / \mathrm{s})$

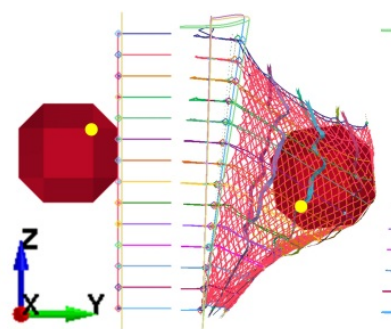

0s $\quad 0.20 \mathrm{~s}$

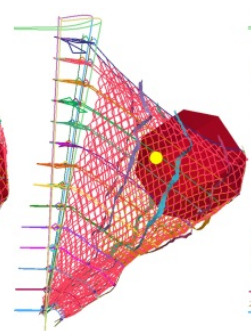

$0.32 \mathrm{~s}$

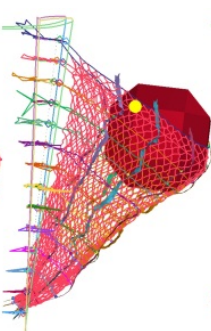

$0.45 \mathrm{~s}$

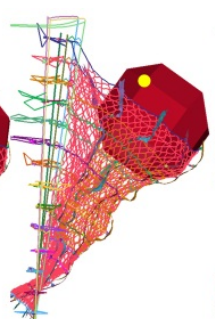

$0.55 \mathrm{~s}$

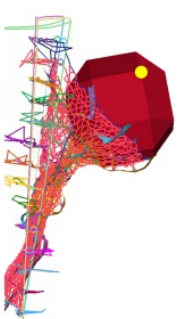

$0.70 \mathrm{~s}$

Fig. 35 Composite picture in Model No. 2 under $E(1000 \mathrm{~kJ})$ and $\omega(18 \mathrm{rad} . / \mathrm{s})$ 


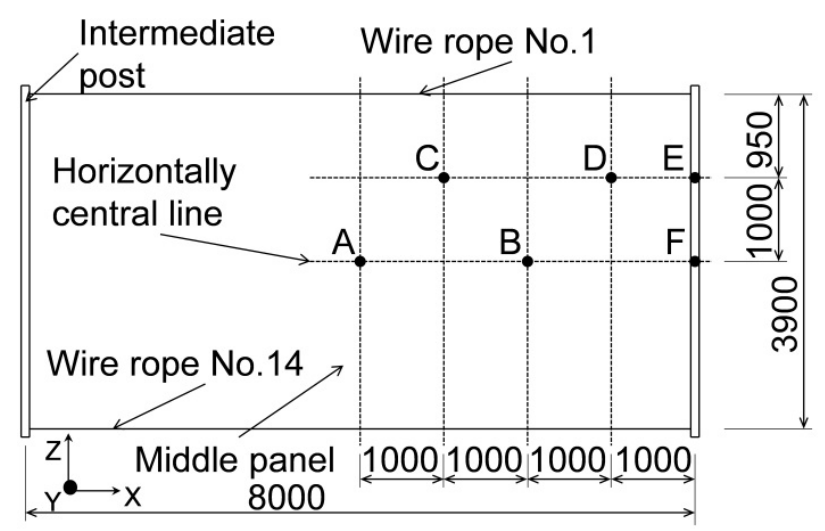

Fig. 36 Map of-impact locations 